\title{
Cultural proximity and the formation of lending relationships
}

CAGE working paper no. 514

September 2020

Antonio Accetturo

Giorgia Barboni

Michele Cascarano

Emilia Garcia-Appendini 


\title{
Cultural Proximity and the Formation of Lending Relationships*
}

\author{
Antonio Accetturo $^{\mathrm{a}}$, Giorgia Barboni ${ }^{\mathrm{b}}$, Michele Cascarano $^{\mathrm{a}}$, and Emilia \\ Garcia-Appendinic \\ ${ }^{a}$ Economic Research Unit, Trento, Bank of Italy \\ ${ }^{\mathrm{b}}$ University of Warwick, Warwick Business School and CAGE \\ ${ }^{\mathrm{c}}$ Department of Banking and Finance, University of Zurich
}

September 2020

\begin{abstract}
We use credit registry data from the population of loans granted to firms in a region hosting two different cultural groups to study the role of culture in the formation of lending relationships. We find a large predominance of lending relationships involving banks and firms of the same culture, particularly among small, young, and opaque firms. Loans to same-culture firms are larger, require less collateral, and default less often than loans to different-culture firms. Our results suggest that cultural proximity reduces information asymmetries by providing a source of soft information that complements the one stemming from close or lengthy relationships.
\end{abstract}

JEL classification: G21, G30, Z1

Keywords: Cultural proximity; Asymmetric information; Soft information; Lending relationships

${ }^{*}$ We thank Audinga Baltrunaite, Martin Brown, Hans Degryse, Silvia Del Prete, Lionel Nesta and Marina Eliza Spaliara, and especially Francesca Modena, as well as participants in seminars at Princeton University, Bank of Italy, Università Politecnica delle Marche, University of Trento, University of Bolzano, Warwick University, and the SIE Società Italiana degli Economisti Annual Meeting for useful comments in preliminary versions of this paper. Garcia-Appendini gratefully acknowledges financial support from the European Research Council (ERC) under the European Union's Horizon 2020 research and innovation programme ERC ADG 2016-GA under grant agreement No. 740272: lending. The views expressed in the paper are entirely the responsibility of the authors and should not be attributed to the Bank of Italy. 


\section{Introduction}

In perfect capital markets, profitability should be the sole determinant of investment and capital allocation decisions. However, real-world financial and economic transactions often deviate from this paradigm, occurring with higher likelihood when the involved parties share the same language, religion or ethnic origin - more in general, when they have a common cultural background (see, for example, Melitz, 2008; Guiso, Sapienza, and Zingales, 2009; Bottazzi, Da Rin, and Hellmann, 2016). Driven by this observation, a large body of literature has investigated the costs and benefits of financial transactions occurring within such culturally proximate groups (Giannetti and Yafeh, 2012; Ahern, Daminelli, and Fracassi, 2015; Fisman, Paravisini, and Vig, 2017; Haselmann, Schoenherr, and Vig, 2018). However, these studies have devoted little attention to why these transactions occur in the first place: How often do parties engage in culturally proximate transactions? Which types of agents are more likely to transact with culturally proximate counterparties? Why and under which conditions do we observe transactions occurring among agents that are culturally diverse? More generally, which market frictions, if any, can explain the prevalence of transactions occurring within culturally proximate agents?

In this paper, we analyze these questions empirically in the context of credit markets by using credit registry data containing the universe of loans disbursed to firms in the bi-cultural region of South Tyrol. South Tyrol is a region in Northern Italy located at the border with Austria and Switzerland where two cultural groups, German and Italian, co-exist by law. ${ }^{1}$ Both Italian and German are official languages, and the two cultural groups live next to each other within municipalities. However, both cultural groups live relatively segregated lives, which enables them to preserve their cultural identities. Importantly for our study, the province includes a large number of firms from a wide range of industry sectors, which are

\footnotetext{
${ }^{1}$ Throughout this text, we will refer to people who speak German or a regional version of standard German interchangeably with the phrases "Germanic culture" or "German culture".
} 
subject to the same institutional, regulatory, and legal framework. By the same token, banks operating in the region consist both of regional and national banks which are also subject to a common regulatory and legal framework which is set at the national level. Thus, South Tyrol represents an almost ideal setting for studying cultural heterogeneity in lending while keeping all other institutional factors fixed (Fernández, 2011). This is especially relevant for the research questions we want to tackle, as institutions are endogenously determined with culture (Tabellini, 2008). In addition, credit markets are particularly well suited to answer our research questions, as they allow us to analyze the role of market frictions, such as information asymmetries and enforcement costs, in the creation of culturally proximate lending relationships.

We start our analysis by documenting that the proportion of loans between banks and firms that share a cultural origin is twice as large as the one implied by random matching between firms and banks given their presence in the local markets. This correlation suggests that there is a strong selection in lending relationships where borrowers and lenders share similar cultural endowments. We advance two main hypotheses to explain this stylized fact. Our first hypothesis is that cultural proximity overcomes frictions in the credit markets, such as information asymmetries (information hypothesis). In fact, if speaking the same language and sharing a common set of behavioral rules and social conventions can facilitate the transmission of subtle signals about the firm's credit quality, the value of the firm's projects, or the management's propensity to engage in moral hazard, then cultural proximity should ease the access of credit to the most opaque firms. Our second hypothesis to explain the prevalence of culturally proximate lending relationships is that borrowers expect a more favorable treatment from lenders which might belong, or be close to, their social network (favoritism hypothesis). In this case, borrowers apply more often for credit to a lender of their same culture, and the observed higher prevalence of culturally proximate loans would simply reflect the higher numerosity of loan applications from borrowers sharing cultural 
traits.

A preliminary exploratory analysis seems to favor the information hypothesis, as we find that firms that borrow from culturally proximate banks present several features that are usually associated to information asymmetries: They are on average younger, smaller, and have larger sales growth than firms borrowing from different-culture banks (Berger and Udell, 1998). Moreover, we also find that some banks tend to specialize in lending to culturally proximate firms. These banks tend to be smaller cooperative banks, which generally employ soft-information-based lending technologies that are better suited to resolve agency problems (Berger and Udell, 2002).

The granular level of our data allows us to analyze the role of cultural proximity in the formation of lending relationships in greater detail, by decomposing the credit process into the loan application phase (demand for credit), the credit screening process (supply of credit), and the lending outcomes (ex-post performance). Our analysis of the loan application process shows that firms are up to 0.76 percentage points more likely to apply for a loan with a bank of their same culture. This result cannot be explained by time-varying or time-invariant firm or bank characteristics, as it is robust to controlling for firm-time and bank-time fixed effects. It also cannot be explained by the plausibly higher likelihood of finding culturally proximate banks in the close vicinity, as we control for the presence of nearby bank branches in our specifications. It is also economically significant, as it compares with a $1.4 \%$ unconditional probability of applying for a loan on any random bank in their locality. While this result is consistent with both our hypotheses, when we extend our analysis to explore heterogeneity across firms with different characteristics, we find that the larger propensity to apply for loans of the same cultural group is highest for the firms with acute information asymmetries: Young startups, small firms, and high growth firms. Moreover, applications for loans from culturally proximate banks decreases sharply with size and age, suggesting that borrowers rely on cultural proximity mostly when their levels of opaqueness are highest. This result 
is once again consistent with a central role of cultural proximity in reducing information asymmetries.

Our analysis on the supply side of credit reveals that lenders are not more likely to approve a loan application from culturally proximate borrowers, a finding that does not line up with the favoritism hypothesis. However, we do find that banks provide larger loans, and are less likely to require collateral, from borrowers that share their same origin. While the latter result might be interpreted as evidence of favoritism, a further analysis suggests that there is a larger dispersion in the terms of loans provided to culturally proximate borrowers. This result is, once again, consistent with the information hypothesis, as it suggests that cultural proximity reduces the information asymmetries in the credit transaction by improving the precision of the signal that the lender obtains about the borrower's creditworthiness (Cornell and Welch, 1996; Fisman et al., 2017). Importantly, this result is robust to controlling for other sources of soft information available to the bank, such as the one collected through personal interactions (i.e., whether the bank is situated in close geographical proximity to the firm; Petersen and Rajan, 2002) or through long-time interactions (i.e., the length of pre-existing relationships, Petersen and Rajan, 1995). This result suggests that the cultural proximity is able to convey soft information over and beyond the one conveyed through personal interactions.

Our final analysis shows that loans to culturally proximate borrowers perform better than loans to distant borrowers. This result supports once more the information hypothesis, while strongly rejecting the favoritism hypothesis. Combined with the results that show lower collateral requirements and higher loan amounts for culturally proximate loans, this finding suggests that the mechanism through which cultural proximity reduces information asymmetries is by facilitating the screening of loan applications. Indeed, loan terms are decided at the outset of the lending process; the fact that same-culture firms obtain better and more precise loan conditions suggests that the pool of accepted borrowers of the same 
culture has a lower average level of risk than different-culture borrowers - which is consistent of the idea of lenders minimizing risks (Strahan, 1999). At the same time, the lower riskiness of the pool of same-culture borrowers might explain why lenders are able to provide them with more favorable terms.

All in all, our paper shows that cultural proximity represents a major determinant in the formation of lending relationships. Moreover, our results provide strong evidence that cultural proximity helps reducing information asymmetries in the lending process, thus explaining how sharing a common cultural background can lead to improved economic outcomes.

Our paper contributes to the literature that studies the role of cultural ties in economic and financial exchanges (see, for example, Guiso, Sapienza, and Zingales, 2009; Disdier and Mayer, 2007; Rose, 2000; Helpman, Melitz, and Rubinstein, 2008; Accetturo, Cascarano, Degasperi, and Modena, 2019). Most of these studies highlight the roles of trust and social capital, transaction costs, and bilateral affinity in the emergence of same-culture transactions. Our results contribute to this literature by providing evidence that information asymmetries can also play a role in the emergence of transactions of the same culture.

Our work is particularly close to recent papers studying the effects of cultural and social proximity on lending outcomes, including loan quality (Fisman, Paravisini, and Vig, 2017; Haselmann, Schoenherr, and Vig, 2018). Differently to these papers, our study is based on the population of loans disbursed in a culturally diverse environment. As such, it allows us to study the endogenous formation of lending relationships based on cultural proximity, and to better understand its role both on the demand and supply of credit. Similarly to our paper, Fisman, Paravisini, and Vig (2017) document an important role of cultural proximity in reducing information asymmetries and improving loan performance. We complement their study by showing that cultural proximity plays a role in the reduction of information asymmetries in all stages of the lending process, and that information contained in cultural proximity is distinct from the one contained other sources of soft information. 
Finally, our paper adds to the literature on credit relationships formation and performance (Berger et al., 1995; Petersen and Rajan, 1995) by showing that cultural proximity represents an additional source of soft information beyond the information that can be collected through geographical proximity or lengthy relationships. Our results show that cultural proximity provides lenders with an additional signal of credit quality which enables lenders to provide credit terms that are commensurate with their creditworthiness.

From a policy perspective, our findings highlight the importance of local banks in lending to small businesses (Angelini, Di Salvo, and Ferri, 1998; Barboni and Rossi, 2019). By sharing the same culture as the firms in the markets where they operate, these financial intermediaries may play a key role in promoting access to credit, particularly for more informationallyopaque firms.

\section{Institutional setup: Cultural heterogeneity in South Tyrol}

South Tyrol ("Provincia di Bolzano" in Italian) is a North-Italian region located at the border with Austria and Switzerland. Before the First World War, the region was part of the Austro-Hungarian princely County of Tyrol; its history as an Italian administrative unit followed the defeat of the German and Austro-Hungarian Empires and the annexation of the territory to Italy.

At the time of the annexation, $89 \%$ of the population spoke German, $3 \%$ spoke Italian, and the remainder of the population spoke either Ladin or other languages of the AustroHungarian Empire (Istituto Provinciale di Statistica, 2015). However, this situation changed shortly after, as the fascist government initiated a process of "Italianization" of the region which favored both the immigration of Italian speakers from other regions and the outmi- 
gration of German speakers to Germany and Austria. ${ }^{2}$ Among other changes, this process permanently altered the distribution of the population across both linguistic groups. As of the last available census, in 2011 the share of German-speaking population was $69 \%$, while Italian speakers accounted for slightly more than one-quarter of the total population.

The current institutional framework of South Tyrol dates back to 1972, when a "Statute of Autonomy" was granted to the region. Among other issues, the 1972 agreement established the right for citizens to use their own mother tongue in all occasions. The application of this right has enabled the two linguistic groups to preserve their culture, as everyday life activities - such as childcare, eldercare, and schooling - are separated for each language group. In fact, segmentation in everyday life is a feature that characterizes the South Tyrolean society (Forer et al., 2008) despite the fact that almost $80 \%$ of South Tyrolean students are proficient in both languages (Vettori and Abel, 2017).

Importantly for our study, South Tyroleans face the same institutional and economic setup in spite of the strong segmentation of their everyday lives. For example, the regulations for all banks that operate in the region are defined at the national level. Similarly, all firms headquartered in South Tyrol are subject to autonomous regulations that are set at the province level (and agreed upon by both cultural groups, to avoid the empowerment of one over the other), ${ }^{3}$ and the chamber of commerce of the province is in charge of their enforcement. Thus, banks and firms in our study share a common legal and regulatory framework which is independent of the cultural origin of their owners or managers. Overall, the fact that German and Italian speakers face the same formal institutional setting but live in an extremely segmented society makes South Tyrol an ideal setting for studying the role of cultural proximity on economic outcomes without confounding factors such as institutions,

\footnotetext{
${ }^{2}$ This was part of the so-called Agreement on the Options of Citizenships between Fascist Italy and Nazi Germany (that had already annexed Austria) in 1939. See Accetturo et al. (2019) for more historical details on the Italianization process.

${ }^{3}$ According to the "Statute of Autonomy", all local governments must be composed at least by one German- and one Italian-speaking party.
} 
norms, geographical distance, among others (Fernández, 2011). In addition, there is a wide geographic variation in the composition of the linguistic groups across the region. Figure 1 illustrates the distribution of Italian speakers in South Tyrol. The majority of the municipalities in South Tyrol are predominantly German speaking, but there is significant variation across towns. As a consequence of the Italianization process, the largest concentration of Italian speakers is located in the valleys close to the cities of Bolzano and Merano. Although municipalities differ considerably on the proportion of the Italian-speaking population, there is no geographic segregation between citizens within municipalities and the vast majority of the population (96.1\%) shares a common Roman Catholic religion.

\section{Data, descriptive statistics and stylised facts}

\subsection{Data sources}

Our main source of data in this analysis is the Italian Central Credit Registry (CR), owned and administered by the Bank of Italy. The CR contains information about all performing and non-performing loans extended by all banks and financial companies that operate in Italy. From this database, we obtain information on quantities, collateral, and status (performing or non-performing) of all loans extended to firms headquartered in the South Tyrol region over the period 2005 to 2015. For a loan observation to appear in the CR, the legal reporting threshold is a total borrower exposure of 30,000 euros towards a given financial intermediary; however, this threshold was 75,000 until December 2008. Following the related literature, to ease comparability throughout all years in our sample period we only consider firm-bank pairs for which the total granted amount is greater than 75,000 euros (Cingano, Manaresi, and Sette, 2016).

From the CR, we also obtain information on loan applications. We follow Albertazzi, Bottero, and Sene (2017) and identify a loan application whenever an intermediary lodges a preliminary information request (Servizio di Prima Informazione, SPI) about the borrower. 
An SPI is an enquiry made by a bank about the current credit position of a potential borrower. Such enquiries can be placed at a small cost for the financial intermediary, only when the intermediary receives a formal request for credit from an individual or a firm. As we explain in more detail in Section 4, we use information on the SPI and existing loans in the CR to proxy for credit demand and credit supply.

The CR contains the unique tax identification of the borrowers. We use this information to obtain the firms' number of employees (which we use to measure firm size) from the Italian Social Security Service (INPS), which gathers this information for all active Italian firms. We also use this information to obtain from a third dataset, Infocamere, the names, gender, place of birth, and age for all members of the firms' management and executive boards. Infocamere is maintained by the Italian Chamber of Commerce and contains management information for all the firms that are headquartered in South Tyrol. Following a similar procedure as in Bedendo, Garcia-Appendini, and Siming (2018), we use this information to manually classify the cultural origin of all administrators, which is used to identify the firms' overall cultural origin (see Online Appendix A for more details).

For all the banks in our sample, we obtain balance sheet information from Bank of Italy's supervisory reports, and information about the management board from the Segnalazione sugli Organi Societari (Or.So.) database. Or.So. is maintained by the Bank of Italy and records information on the names, gender, place and date of birth of all the members of the governing bodies and the top executives of each bank. Using the same procedure as for firms, we classify a financial intermediary as belonging to an Italian (Germanic) cultural group if the majority of the members of the board and top executives are of Italian (Germanic) cultural origin.

Mostly due to data availability, we focus on the management board to classify the cultural origin of banks and firms (see Infante and Piazza, 2014 for a similar approach). To the best of our knowledge, there are no available data sets with the names and gender for other 
employees, such as the loan officers. However, this is not likely to represent a large limitation for our study, as (i) the credit market in the South Tyrol region is dominated by local banks, where the distance between the firm and the bank board is quite limited (Benvenuti, Casolaro, Del Prete, and Mistrulli, 2017) and (ii) the vast majority of firms in the region are small, privately held establishments where owners and managers are likely to be the same person, or linked by family (and hence, cultural) ties (Bedendo, Garcia-Appendini, and Siming, 2018).

\subsection{Descriptive statistics}

Table 1 presents basic descriptive statistics of the CR sample. On a given year in our sample period, our dataset contains loan-level information on more than 8,000 unique firms and roughly 200 unique banks, for a total of 13,469 unique firms and 361 unique banks over our sample period. According to the 2011 census, firms headquartered in South Tyrol were 43,000 including artisans, independent contractors, freelance workers, and cooperatives. Thus, our sample - which only considers firms that have a borrowing relationship with the banking system over the reporting threshold and with a precise cultural classification - covers a large fraction of the universe of the South Tyrolean firms.

Table 1 also shows that the percentage of Italian firms is relatively low (23\%-25\%) and reflects population shares, suggesting that entrepreneurship rates are quite similar in the Germanic and Italian cultural groups. The larger percentage of Italian banks reflects the fact that all Italian banks may operate in the South Tyrolean credit market with at least one lending relationship.

Table 2 contains summary statistics on firms, banks, and bank-firm relationships. Firms in our sample are 16 years old on average. They are relatively large compared to the population: the average number of employees in our sample is 17 , whereas it is 4 when calculated using census data. The median size is much lower than the average (5.5 employees), and the standard deviation is several times the average (144), suggesting that our data contains some 
large firms which are more likely to have a credit relationship with a bank. Each firm has outstanding links with an average of 1.6 banks. However, the variation is very large: the standard deviation in the number of banking relationships is 1.4, and almost $70 \%$ of the firms in our data have only one banking relationship. The average number of bank links within the same cultural groups is 1.1, implying that the majority (72.7\%) of all bank-firm relationships in the region are established within the same group.

Regarding the banks in our sample, we observe that around half (48\%) correspond to credit cooperatives. The average log size of a bank corresponds to 1.2 billion euros in total assets; the average assets to capital ratio is 12 , implying a leverage ratio of $8.3 \%$. Finally, the ratio of non-performing loans over total loans is $11 \%$.

Table 2 also shows that the average log length of the relationship between a firm and a bank corresponds to 5.4 years, and the average (median) of the log of granted loan size corresponds to around half a million $(400,000)$ euros. One-third of all loans are collateralized, while the share of Non-Performing Loans (NPL, which include bad loans and other minor anomalies such as loans that are unlikely to be paid back and overdue loans) is $10 \%, 8.7 \%$ of the total corresponding to minor anomalies. ${ }^{4}$

\subsection{Stylised facts on cultural proximity}

The results in Section 3.2 show that the choice of culture of lenders and borrowers is not a random choice. Indeed, from Table 1 , we observe that $77 \%$ of the firms and $25 \%$ of the banks are of Germanic origin. If the choice of culture of lenders and borrowers were randomly assigned, then roughly $36 \%(=0.77 \times 0.25+0.23 \times 0.75)$ of all lending relationships should belong to firm-bank pairs sharing the same cultural origin. However, the fraction of samegroup relationships, which we observe in Table 2, is twice as large (72.7\%). This finding

\footnotetext{
${ }^{4}$ According to the Bank of Italy classification, minor anomalies comprise two specific categories of NPLs, aside from bad loans: i) unlikely-to-pay exposures (loans which banks believe the debtors are unlikely to meet their contractual obligations in full unless action such as the enforcement of guarantees is taken), ii) overdrawn and/or past-due exposures (loans that are overdrawn above a predefined amount and/or are past-due by more than 90 days).
} 
represents our first stylized fact regarding the role of cultural proximity in the lending process:

Stylized fact 1. The observed fraction of firms borrowing from a bank of its same cultural group is twice as large as the one implied by random matching between firms and banks.

Stylized fact 1 suggests that culture is an important determinant of the existence of a transaction. We next provide a first blush analysis of why this might be the case, by analyzing the characteristics of firms (demand-side of credit) and banks (supply-side of credit) that correlate more strongly with same-group lending.

To analyze the characteristics of firms borrowing from same-culture banks, we collapse the CR dataset at the firm-level, obtaining approximately 90,000 firm-year observations. We then use univariate tests of differences in means to compare characteristics of firms that borrow exclusively from banks of their same cultural group with those of firms that borrow from at least one bank of a different culture. Results are shown in Table 3.

We find that firms that borrow exclusively from banks of the same cultural origin are slightly younger, and significantly smaller, on average, than firms that form relationships with banks of a different cultural origin. The former firms have also fewer lending relationships than firms that form relationships with banks of a different cultural origin, and their sales growth is slightly higher. All these characteristics are typical of startups or firms in their early life cycle, and are usually associated with high informational opaqueness (i.e. Berger and Udell, 1998). These results suggest that same-group lending might be preferred in the early stages of a firm's life cycle, when the levels of information asymmetries between borrowers and lenders are particularly acute. From these findings we derive the second stylized fact:

Stylized fact 2. Firms borrowing exclusively from same-culture banks are younger, smaller, and have larger sales growth than firms borrowing from different-culture banks.

We next turn into the supply side of credit by comparing the characteristics of banks lending to a high fraction of firms of the same cultural group, relative to banks lending 
to a lower fraction of firms of the same cultural group. For this purpose, we collapse our firm-bank-year level database to the bank-year level, and calculate the fraction of firms in each bank's portfolio that belong to the same cultural group. We then split the bank-year observations at the median of the fraction of borrowers of the same cultural group in each year. ${ }^{5}$ Results from Table 4 show stark differences between these groups: for banks with high fractions of same-group lending, the average fraction of firms of a different culture is only $2.4 \%$, while the other banks lend on average to $63.3 \%$ firms of a different culture. This result suggests that the former banks specialize on same-group lending, while the latter diversify their lending pool across the two cultures.

We also find that banks lending to a large fraction of firms from the same cultural group are significantly smaller, and are more often local credit cooperatives (BCC), than banks lending to a smaller fraction of same culture firms. This suggests that these two groups of banks have different lending technologies, the former group relying more on soft information lending. These findings are in line with the results at the firm level, and also suggest that information asymmetries might be of first-order importance to determine the prevalence of same-culture relationships. This constitutes our third stylized fact:

Stylized fact 3. Banks lending to large fractions of same-culture firms are smaller, and much more likely to be cooperative banks, than those lending to different-culture firms.

Table 4 also shows that banks lending to a large fraction of firms of the same culture are better capitalized, on average, than banks lending more to different-culture firms; however, their ratios of non-performing loans are economically similar across the two groups. These results are not consistent with the idea that banks lending to same-culture firms are of worse quality than banks lending to different-culture firms. ${ }^{6}$

\footnotetext{
${ }^{5}$ The average across all years of the median yearly fraction of borrowers of a different group is $15.4 \%$.

${ }^{6}$ The results in Tables 3 and 4 also hold in a multivariate setting, and are robust to controlling - in a smaller sample for which these observations are available - for other measures of firm and bank risk and performance. See Tables A1 and A2 in Online Appendix B.
} 
Overall, stylized facts 1 to 3 suggest that asymmetric information plays a central role in the matching of firms and banks based on culture. However, the results in this section have two caveats. First, the sample analyzed consists of equilibrium credit outcomes, and cannot inform whether the observed effects are driven by the supply or the demand of credit. Second, these univariate analysis can at most show correlations between the variables. In the next sections, we decompose the formation of lending relationships into the loan application process, a subsequent loan approval process, and an analysis of loan performance, in order to explore these issues further.

\section{Cultural proximity and the formation of lending re- lationships}

\subsection{Credit demand}

In this section, we analyze the impact of culture on the formation of new credit relationships from the demand-side of credit; that is, we examine the role of cultural proximity in firms' selection of a lender bank. For this purpose, we simulate the loan application process by creating a database with all the possible pairs of firms and banks that operate in the same local labor market in each period. This database represents all the potential banks where a firm could submit an application for a loan. The underlying assumption of relating banks and firms in the same local labor market is that, when deciding to apply for a loan, a firm could potentially apply to any branch of banks operating locally. This assumption builds on prior findings that suggest that most lending is done at a local level (Petersen and Rajan, 2002; Degryse and Ongena, 2005). Based on this expanded database, we use the regulatory database Servizio di Prima Informazione (SPI) to create a binary variable, LoanApplication $_{i j t}$, which equals one if firm $i$ requested a loan from bank $j$ during year $t$, and zero otherwise. Recall that the SPI dataset contains requests for information about firms lodged by banks in the credit registry. Presumably, only banks that have no prior 
information about the borrower will lodge such a request for information; thus, this variable is a good proxy for loan demand. ${ }^{7}$ To analyze whether cultural proximity plays a role in the demand for credit, we regress LoanApplication ${ }_{i j t}$ on the variable SameGroup Sij $_{i j}$, an indicator of whether the bank and the firm belong to the same cultural group or not, and a set of firm-, bank, and relationship-specific controls (respectively $X_{i t}, X_{j t}$, and $X_{i j t}$ ), which are likely to affect the formation of new banking relationships and be correlated with SameGroup $i j$. More formally, we estimate a regression of the following type:

$$
\text { LoanApplication }_{i j t}=\beta_{0}+\beta_{1} \text { SameGroup }_{i j}+\beta_{2} X_{i t}+\beta_{3} X_{j t}+\beta_{4} X_{i j t}+\epsilon_{i j t} .
$$

Table 5 contains the results from estimating different specifications of Equation $1 .{ }^{8} \mathrm{In}$ column 1, we present a benchmark specification in which we only control for the macroeconomic conditions in the region by adding year fixed effects. We find a very strong and positive effect of SameGroup on the creation of a new lending relationship: The coefficient is 0.006 , and it is statistically significant at the $1 \%$ level. Economically, the coefficient is very relevant, as it corresponds to $36 \%$ of the average value of the dependent variable $(0.014)$. However, this coefficient could be biased by demand- and supply-side factors which could be correlated with variable SameGroup.

In columns 2 to 5 , we include bank $\times$ year fixed effects in vector $X_{j t}$. This allows us to control for all time-invariant and time-varying bank characteristics which may affect the supply of credit - including the banks' lending technology and financial conditions, which were shown in the previous section to be correlated with cultural proximity. With these

\footnotetext{
${ }^{7}$ Lodging an inquiry to the SPI is neither compulsory nor costless for the bank, albeit the cost is low, mounting to a few cents on the euro (Branzoli and Fringuellotti, 2020). Similarly, a bank might lodge a request of information for a borrower that did not necessarily apply for a loan at the bank. Thus, analyses using this data could result in a non-classical measurement error, potentially biasing the coefficient towards zero. To address this concern, in undisclosed analyses we proxy for loan demand using an alternative measure that is based on CR data. More precisely, we measure loan demand with a dummy equal to one for all new bank relationships established by the firm in a given period, and zero for all other banks in the same LLM as the firm which do not establish a relationship with the firm. All the results that are discussed in this section are quantitatively and qualitatively robust to this alternative definition of credit demand.

${ }^{8}$ The average value in this expanded database of variable SameGroup is 0.491 , with a standard deviation of 0.500 .
} 
controls, the coefficient of SameGroup is only slightly changed relative to the one in column 1. In columns 3 to 5 of Table 5 , we additionally include variables that affect the demand for new credit, $X_{i t}$. Following Degryse, De Jonghe, Jakovljević, Mulier, and Schepens (2019), we control for credit demand using very granular sets of fixed effects which result from interacting several discrete variables. More precisely, in columns 3 and 5 we include industry $\times$ location $\times$ firm size $\times$ firm age $\times$ year fixed effects. ${ }^{9}$ In column 4 , we control for all time-invariant and time-varying firm characteristics which may affect the demand for credit by adding firm $\times$ year fixed effects (Khwaja and Mian, 2008). The coefficient for variable SameGroup increases relative to the ones in columns 1 to 3 with the inclusion of these demand-side controls.

One concern of the estimations in columns 1 to 4 is that the coefficient for variable SameGroup could be capturing unobserved characteristics that have variation at the firmbank level. In particular, firms might be more likely to demand credit from banks that are located in the closest vicinity within the local labor market (Petersen and Rajan, 2002; Degryse and Ongena, 2005); to the extent that the banks closest to the firm belong to its same cultural group, the coefficient for SameGroup could be capturing this effect. To address this issue, we repeat the estimations of regressions 1 to 4 with the addition of a dummy variable NearbyBranch ${ }_{i j}$ which equals 1 if there is a branch of bank $j$ operating in the close vicinity (i.e. in the same municipality) as firm $i$, and 0 otherwise. ${ }^{10}$ For the benefit of space, we only report the estimated coefficient corresponding to the regression in column 3 augmented with this variable; however, results are very similar (qualitatively and quantitatively) for all other specifications. As illustrated in column 5 , the inclusion of this dummy has virtually no effect on the coefficient of variable SameGroup, implying that its importance cannot be explained

\footnotetext{
${ }^{9}$ Industry fixed effects are dummy variables corresponding to each of the 2013 -digit NACE industrial groups; location fixed effects are the 14 different LLMs in the South Tyrol region; and we consider 4 equallysized bins to control respectively for firm size and firm age. In unreported specifications, we substitute the interacted fixed effects with controls for industry fixed effects, location fixed effects, year fixed effects, firm size, age, growth, and all measurable financial conditions. Results are also qualitatively unchanged.

${ }^{10}$ There are 116 municipalities in the South Tyrol region; thus, this geographical subdivision by municipalities achieves a much more granular subdivision of the region than the local labor market. The mean and standard deviation of variable NearbyBank $k_{i j t}$ are 0.114 and 0.318 , respectively.
} 
away by the physical proximity to the lender bank.

In sum, results in Table 5 show highly significant coefficients for variable SameGroup, which survive to controlling for all possible time-invariant and time-varying factors that affect the supply and the demand for credit, and to the geographical distance between lenders and borrowers. The estimated coefficients correspond to 36 to $54 \%$ of the average value of the dependent variable, showing that cultural proximity is also an economically important determinant in the selection of the lender bank. The central and unique role of cultural proximity in the demand for loans is a central finding of this paper.

\subsection{Heterogeneous effects}

We next explore which firm characteristics relate to the creation of new lending relationships with culturally proximate versus culturally distant banks. In particular, based on stylized facts 1 to 3, we analyze whether opaque firms are more likely to apply for credit from a culturally proximate bank. As mentioned before, if speaking the same language and sharing a common set of behavioral rules and social conventions can facilitate the transmission of subtle signals about the firm's credit quality, the value of the firm's projects, or the management's propensity to engage in moral hazard, then cultural proximity should ease the access of credit to the most opaque firms, and we could expect these firms to recur more often to same-group borrowing.

To test this hypothesis, we use the same sample as in Table 5 and regress variable LoanApplication on SameGroup and interactions of this variable with standard measures of the firms' opaqueness (size, age, and growth). If cultural proximity helps to mitigate information asymmetries, then we should expect small and young firms to rely more strongly on lending from culturally proximate banks; however, this reliance should decrease as the firms grow older and/or larger and hence, become less opaque.

We present the results of this analysis in Table 6. In all of the specifications of this table, 
we control for macroeconomic conditions and supply of credit in the local area by adding industry $\times$ location $\times$ year fixed effects, and by the supply of credit by adding bank $\times$ year fixed effects. We also control for the geographical proximity between borrowers and lenders using variable NearbyBranch.

We start by analyzing the effect of firm age and firm size on loan applications in columns 1 and 2 of Table 6 , respectively. In column 1, we find that the uninteracted coefficient for age is positive and statistically significant. This result shows that the demand for loans from banks of a different cultural group increases as the firms grow older. In addition, the negative and statistically significant coefficient for the interaction term shows that the difference between the demand for loans from banks of same vis-à-vis different cultural groups is reduced as the firms mature. A similar picture emerges when we analyze, in column 2, the effect of size on requests for loans from new banks. Also in this case we observe a positive and significant non-interacted coefficient, and a negative coefficient for the interaction with the same group dummy. In column 3, we interact for both size and age simultaneously and continue to find negative interaction terms of both variables with SameGroup. These results are fully consistent with cultural proximity playing an important role to mitigate information asymmetries: the most opaque firms, which are young and small, rely strongly on same group lending to cover their financing needs. However, as firms become older and larger, they are more and more likely to resort to a bank of a different cultural group. The results continue to hold when we control for firm growth and its interaction with SameGroup, in column 4. In fact, reinforcing the idea that asymmetric information plays an important role in the formation of same group credit relationships, we also find that interaction of firm growth with SameGroup is positive and statistically significant. ${ }^{11}$

\footnotetext{
${ }^{11}$ In an undisclosed analysis available upon request, we run similar regressions as in Table 6 but adding interactions of SameGroup with firm financial conditions, using a sub-sample of firms for which this information is available. We do not find evidence that firm risk or firm quality are correlated with the demand for loans from same group banks. However, all the results discussed above for size, age, and growth continue to hold.
} 
In Figures 2 and 3, we summarize the findings of Table 6 by plotting the marginal effects of firm age and firm size on the likelihood of applying for a loan from a bank of the same or of a different cultural group. We use marginal effects from the estimated coefficients in columns 1 and 2 of Table 6, respectively. Essentially, these specifications capture changes in the preference for financing from different-culture banks during their life-cycle - i.e., as they grow older and larger, and hence, less opaque. The horizontal access in Figure 2 corresponds to firm age (in years) and in Figure 3 to firm size (measured in number of employees).

From Figure 2, we find a decreasing effect of age on demand for loans from new banks of the same culture (red line). The youngest firms in the sample are about 0.5 percentage points more likely to require a loan from a bank of their same cultural group than the oldest firms in the sample. In contrast, as firms become more mature, the probability of requesting a new credit from a bank of a different group increases (blue dotted line). In fact, the youngest firms (i.e., the startups) virtually never seek a new relationship with a bank of a different cultural group, while the oldest firms are 0.4 percentage points more likely than startups to request a loan from a bank of a different group. As a consequence of these two results, the difference between asking for a new loan from a bank of the same vs. a different cultural group is strongly reduced as firms mature (black dotted line).

In Figure 3, we repeat the exercise for firm size, finding similar results as with firm age. In this case, we find a very steep upward-sloping relation between firm size and the probability of requesting a new loan from banks of a different group, and a more gradual decrease in the likelihood of requesting a loan from a same-group bank as the firm grows larger. Similarly to what we observed for firm age, the smallest firms in the sample are also virtually unlikely to request a loan from a bank of a different group, and become increasingly more likely to do so as they grow larger. As it was the case with firm age, the difference between both lines is also decreasing with firm size, as seen by the dotted black line. Results in Figures 2 and 3 are consistent with information asymmetries playing an important role in the choice of the 
culture of the lender bank.

\section{Cultural proximity, credit supply, and performance}

So far, our analysis of the role of cultural proximity in the demand side of the credit market shows that more informationally-opaque firms demand same-culture loans to a larger extent. In this section, we turn to the supply side of credit and study the role of cultural proximity on banks' lending behavior. This is used to understand how cultural proximity affects lending outcomes and, in particular, whether conditional on receiving a loan application, banks favor same-culture with respect to different-culture firms (favoritism hypothesis), or whether same-culture firms are able to obtain better loan conditions because their lenders receive more precise signals of credit quality (information hypothesis). As we explain in more detail below, if borrowers receive a preferential treatment from their same-culture lenders, we should observe that they obtain better loan terms (larger probability of loan approval, or riskier borrowers conditional on approval) but that their loans perform worse than different-group borrowers. If, on the other hand, lenders are able to infer better signals about the credit quality of same-group borrowers, they should be able to offer a loan contract which includes terms that are tailor-made for each borrower, and the performance of these loans should be on average better than different-group loans (Cornell and Welch, 1996).

To assess which of the two hypotheses dominates, we focus on the probability of approving a loan request and on three loan terms: loan quantities, maturity, and collateral requirements. ${ }^{12}$ We also compare the performance of loans provided to borrowers of the same cultural group relative to those provided to borrowers of a different group. More precisely, our analysis of banks' lending decisions is based on the OLS estimation of the following equation:

$$
Y_{i j t}=\beta_{0}+\beta_{1} \text { SameGroup }_{i j}+\beta_{2} X_{i t}+\beta_{3} X_{j t}+\beta_{4} X_{i j t}+\epsilon_{i j t},
$$

\footnotetext{
${ }^{12}$ We cannot analyze the cost of credit because this survey-based information does not include minor financial institutions, which represent the majority of the lending institutions in the South Tyrol region.
} 
where $Y_{i j t}$ measures lending outcomes, and $X_{i t}, X_{j t}$, and $X_{i j t}$ are firm-, bank-, and relationshipspecific controls. In section 5.1 we focus on loan approvals (extensive margin of credit), while in section 5.2 we analyze the loan terms, conditional on loan approval. Finally, in section 5.3 we explore whether there is an impact of cultural proximity on loan performance.

\subsection{Credit supply}

To analyze whether cultural proximity affects the probability of approving a loan (extensive margin of credit), as the dependent variable in Equation 2 we use LoanApproval $_{i j t}$, a dummy variable that equals one if bank $j$ approves a credit request from firm $i$ at time $t$, and zero otherwise. We estimate this equation on the SPI dataset, which allows us to condition our analysis on the set of banks where firms plausibly applied for a new loan. To construct the dependent variable, we assign the value of one to all observations in this database that eventually ended up in the CR database, and a zero otherwise. Loan requests that ended up in the CR indicate the formation of a credit relationship between a bank and a firm that most likely did not have a previous relationship, and thus, are a good measure for an approval of a new loan application. Results of this analysis are contained in Table $7 .{ }^{13}$

Column 1 of Table 7 shows a regression where the only controls added are year fixed effects. The coefficient in this simple specification suggests that the probability banks accept a loan request from a firm of the same cultural group is 3.9 percentage points significantly larger than from a firm of a different group. However, once we control for bank-year fixed effects (column 2), the coefficient of interest loses its statistical and economic significance. From the results in column 2, we cannot reject the hypothesis that cultural proximity does not matter for being successful in loan applications. This result continues to hold after controlling for demand-side controls: industry-size-age-location-year fixed effects (columns 3 and 5) and firm-year fixed

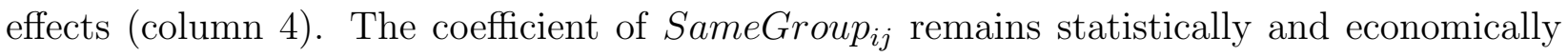

\footnotetext{
${ }^{13}$ The average (standard deviation) of variable SameGroup over this sample is 0.594 (0.491). The average value is slightly higher than in the sample of credit demand, reflecting the higher proportion of same-group borrowers in the pool of loan applicants.
} 
insignificant also after controlling for the availability of soft information potentially obtained through personal interactions, by controlling for the existence of a nearby branch (column 5). The results in columns 2 to 5 - which contain bank $\times$ year fixed effects - can be interpreted as evidence that, within the pool of loan applications a given bank receives, sameculture firms are equally likely as different-group firms to be granted a loan. In other words, banks do not seem to favor firms belonging to the same cultural group when screening loan requests. Rather, conditional on advancing a loan request (which, as we have seen, depends on culture), ${ }^{14}$ firms belonging to the same culture access credit with the same average probability as firms from a different culture.

The results in Table 7 suggest that banks are not more likely to approve loans of sameculture firms. However, in Table 5 we found that banks face a disproportionately larger pool of same-culture applicants. Therefore, it is still possible that banks exert favoritism in the selection process, for example by selecting a pool of same-culture borrowers that is on average riskier than the pool of different-culture borrowers. If this were the case, then we should observe that banks offer same-group borrowers loan terms that allow them to control their risks better - for instance, by granting smaller or shorter-term maturity loans (Strahan, 1999; Diamond, 1993), or by requiring collateral more often (Bester, 1985; Berger and Udell, 1990) - in order to minimize potential losses. We explore this in the next section.

\subsection{Loan terms}

For our analysis of loan terms we focus on the complete CR data, which contains all active bank-firm relationships during our sample period. ${ }^{15}$ As mentioned above, the loan terms we can study in our data are the loan size (intensive margin of credit), maturity, and collateral

\footnotetext{
${ }^{14}$ This is a relevant qualification to interpret our results. As we have seen in the previous section, culture is extremely relevant in the demand for loans. This implies that the loan approval process occurs in a selected sample. Stated in a different way, our coefficients in this section must be interpreted as a "treatment effect on the treated" rather than a (more general) "treatment effect" (Heckman, Urzua, and Vytlacil, 2006).

${ }^{15}$ Our analysis of loan terms contains all approved loans in the CR, and as such, the number of observations is larger than the sample in Table 7, which only considers applications for loans with banks that had no previous relationship with the firm.
} 
requirements. The dependent variable $Y_{i j t}$ in Equation 2 corresponding to each of these loan terms is respectively the natural logarithm of the granted loan amount, a dummy equal to one if the loan has a long-term maturity, and a dummy equal to one if the loan is collateralized. ${ }^{16}$ Results of these estimations are shown respectively in Panels A, B and C of Table 8. For consistency, each column in this table contains the same set of fixed effects as those in Tables 5 and 7.

\subsubsection{Loan size}

From Panel A of Table 8, we can see that there are no statistically significant differences in the loan size offered to same- versus different-culture firms when we only control for year fixed effects. However, once we control for supply- and demand-side characteristics, the coefficient for SameGroup becomes positive and statistically significant. Results in columns 2 to 5 of Panel A show that, conditional on obtaining a loan, same-culture borrowers of a given bank receive between $3.2 \%$ and $5.5 \%$ significantly larger loans than different-culture borrowers. From column 5, we observe that these results are robust to controlling for other potential sources of soft information available to the bank: information obtained through personal interaction (as proxied by NearbyBranch), and information collected through previous interactions between the firm and the bank. We measure the latter by introducing variable RelationshipLength, which is defined as the log of one plus the number of years of duration of the bank-firm relationship.

Notably, the positive and statistically significant coefficient for SameGroup is also robust to the inclusion of firm $\times$ time fixed effects in column 4 , albeit with a smaller statistical significance. Thus, the larger loan terms for same culture firms is robust to controlling for all observable and unobservable time-varying demand- and supply-side characteristics. However,

\footnotetext{
${ }^{16}$ In case a firm has more than one loan outstanding with the same bank in a given year, we aggregate to the firm-bank-year level by adding the total granted amounts over all loans outstanding on that year, calculating the fraction of the approved amount that corresponds to term loans (long-term debt), and assigning a value of one to the collateral dummy if the bank requires collateral on at least one of the firm's loans.
} 
the results in this specification are less precisely estimated relative to those in the rest of the columns. The reason of this lower precision could be that the sample in this regression is necessarily restricted to firms that borrow from more than one bank, with at least one of them in the same cultural group and another in a different group as the firm. Based on previous findings, this sample is plausibly biased towards the relatively larger firms in the sample which borrow from banks of both cultures; cultural proximity is less likely to be relevant for these firms. For this reason, our preferred specifications in this table are columns 3 and 5 .

The positive and statistically significant coefficient for loan size is not consistent with banks lending to a riskier pool of same-culture borrowers. If this were the case, we would expect banks to limit their exposure to these riskier borrowers by providing smaller loans (Strahan, 1999). Instead, across the different specifications we find that loans provided to same-group borrowers are larger.

\subsubsection{Loan maturity}

We next analyze whether there is an effect of culture on loan maturity. In principle, debt maturity should reflect optimizing firms' choices in terms of cash flow management, production decisions, and investments. However, if credit markets are imperfect, lenders might prefer to grant shorter-term loans to riskier borrowers to hedge their risks (Strahan, 1999), increase their protection through the higher seniority of short-term debt (Diamond, 1993), and overcome moral hazard problems by monitoring more frequently (Diamond and Rajan, 2001) and/or reducing incentives to engage in asset substitution (Dennis, Nandy, and Sharpe, 2000). Thus, following the above arguments, a larger proportion of short-term loans among same-group borrowers would be consistent with the idea that same-group borrowers are riskier, and thus, that there was some degree of favoritism towards same-group firms in the selection process.

To explore this issue, in Panel B we estimate Equation 2 using the share of term loans over 
total debt as a dependent variable. ${ }^{17}$ Results show an economically small and statistically insignificant coefficients for variable SameGroup throughout the specifications. This evidence is not consistent with same-group borrowers being riskier than different-group borrowers.

\subsubsection{Collateral}

Finally, in Panel $\mathrm{C}$ of Table 8 we analyze the role of cultural proximity in loan collateralization. Theories of collateral as a screening device assume that borrowers for whom lenders have a relatively smaller information advantage should face higher collateral requirements (Bester, 1985; Chan and Kanatas, 1985; Inderst and Mueller, 2007). Thus, if cultural proximity provides an information advantage for same-group lenders, we should expect a lower collateralization rate for same-group firms. On the other hand, if lenders are favoring samegroup borrowers in the loan selection process, they might end up with a riskier pool of same-group borrowers. In this case, we would expect banks to require same-group borrowers to post collateral with a larger probability, in order to hedge their risks. Results in column 2 of Panel $\mathrm{C}$ show that the share of collateralized loans is on average 2.3 percentage points significantly lower for same-group borrowers of the same bank. ${ }^{18}$ The negative coefficient continues to be statistically significant in columns 3 and 5 . Interestingly, the negative coefficient disappears when we control for firm $\times$ year fixed effects in column 4 , where the sample is plausibly biased towards larger firms for which soft information contained in cultural proximity matters less. Thus, in line with what we found in Panel A, results in Panel $\mathrm{C}$ also suggest that cultural proximity provides an information advantage to lenders, which allows them to offer lower degrees of collateralization to the borrowers.

\footnotetext{
${ }^{17}$ The CR contains information on three types of loans (so-called technical forms): (i) revolving credit lines; (ii) loans backed by accounts receivable; (iii) term loans. Revolving credit lines and loans backed by accounts receivable are generally short-term loans, and term loans tend to be long-term loans without the possibility for the bank to revoke them if the economic condition of the borrower deteriorates.

${ }^{18}$ In principle, the collateralization rate may depend on the debt composition, as not all types of loans are usually guaranteed with collateral. Longer-maturity term loans are often covered by collateral. As shown in Table A3, results are qualitatively similar when we restrict our analysis to term loans. However, statistical significance is reduced, possibly due to the smaller sample size.
} 


\subsubsection{Loan terms dispersion}

Results from Table 7 show that banks are not more likely to grant a loan to firms of their same cultural background; and from Table 8 we do not find evidence that same-group borrowers are riskier, on average, than different-group borrowers. Instead, the findings on larger loan amounts and lower probability of posting collateral for same-group borrowers are consistent with cultural proximity providing banks with an information advantage which allows them to offer better loan terms (i.e. larger loan size, lower collateral requirements) to same-culture firms. The relevance of information asymmetries is highlighted by the fact that the statistical significance of these results is reduced in the specifications with firm $\times$ time fixed effects, where the sample contains larger and older firms where soft information is plausibly less relevant.

An alternative interpretation of the previous results is that banks do not favor same-group borrowers in the loan screening process by approving their loans with higher probability (Table 5), but they do offer them better lending conditions conditional on approval, leading to the observed larger loan sizes and lower collateral requirements. To disentangle across the two interpretations, we compare the dispersion in the loan terms of borrowers of the same group vs borrowers of a different group of a given bank. Our conjecture is that if banks have an information advantage of lending to same-group borrowers, they should be able to set more precise loan terms for these borrowers. That is, banks can target same-culture firms with a more precise credit supply and credit conditions. Hence, we should observe a higher dispersion in the loan terms of same-culture firms vis-à-vis different culture ones (Cornell and Welch, 1996; Fisman, Paravisini, and Vig, 2017).

To perform the analysis of dispersion, we collapse our firm-bank-year CR dataset and create a database containing two observations per bank and year: one with summary statistics about loans provided to same group firms, and another one for different-group firms. We then estimate the following regression equation: 


$$
\sigma(Y)_{b g t}=\beta_{0}+\beta_{1} \text { SameGroup }_{b g t}+\beta_{2} \bar{X}_{b g t}+\nu_{b}+\delta_{t}+\epsilon_{b g t} .
$$

In the above equation, $g$ is an index for each the two cultural groups, and $\sigma(Y)_{b g t}$ is the standard deviation of variable $Y$ (i.e. log of the granted loans or the collateral ratio) for all loans made by bank $b$ at time $t$ to cultural group $g$; it measures the dispersion in the loan terms, and hence, the precision with which banks assign loan terms to their borrowers. SameGroup is a dummy taking the value of one when $g$ refers to summary statistics for borrowers of the same cultural group and 0 otherwise; $\bar{X}_{b g t}$ is a vector of averaged controls; and $\nu_{b}$ and $\delta_{t}$ refer respectively to bank and year fixed effects. The variable of interest is SameGroup. If $\beta_{1}>0$, the dispersion in variable $Y$ is larger for the credit granted to the same cultural group, suggesting that banks can provide more tailor-made loan terms to loan applicants that belong to their same cultural group.

Results from the analysis of loan dispersion is shown in Table 9. We observe that loans lent by banks to same-culture firms are characterised by a significantly higher average dispersion for loan size ( +0.11 s.d.), maturity ( +0.03 s.d.) and collateralization $(+0.02$ s.d.). These results remain of the same magnitude and significance also after controlling for average groupbank relationship indicators, such the fraction of borrowers of each group that is located near the bank, and the average length of firm-bank relationship.

The analysis of loan dispersion strongly supports the "information advantage" hypothesis on the role of culture in credit markets: if banks exert any favoritism towards same-culture firms, this seems to be driven by a better screening performed through the lenses of a common cultural background. In the following section, we provide further evidence of the informational role of cultural proximity by comparing the ex-post performance of same- versus different-culture loans. 


\subsection{Lending performance}

As a final test for whether cultural proximity leads to lending favoritism, or whether it is a lending technology that allows to reduce information asymmetries, we estimate Equation 2 on the sample of loans in the CR, substituting the dependent variable, $Y_{i j t}$, with observed ex-post loan quality. In Panel A of Table 10 we measure loan quality using non-performing loans (NPL), a dummy equal to one if bank $j$ registered its loan with firm $i$ in year $t$ as a nonperforming loan anytime between years $t$ and $t+3 .^{19}$ NPLs are a very broad definition that includes bad loans and loans with minor anomalies (such as unlikely to be repaid, overdues, etc.). According to Italian rules, the decision to register a bad loan is based on the banks' assessment of the borrower's economic situation. Thus, in principle, this variable could be influenced by the fact that banks and firms may belong to the same cultural group. To deal with this problem, in Panel B we exclude bad loans and we only use minor anomalies (a subset of NPLs which are less subject to the bank's assessment) as an alternative dependent variable.

Column 1 in Panel A shows that loans to same-culture firms are 1.6 percentage points less likely to be registered as non-performing than loans to different-culture firms. Economically, this corresponds to $15 \%$ of the average value of the dependent variable $(0.101)$, and it is statistically significant at the $1 \%$ level. With the exception of column 4 - which, as mentioned before, consists of larger firms for which information asymmetries are likely to be less of a concern -, this result does not change qualitatively in the rest of specifications of Panel A. Panel B shows similar findings: when we concentrate on minor anomalies, the point estimate ranges between -8 and -18 percentage points, with a mean dependent variable equal to $8.7 \%$. Overall, results from Table 10 provide evidence of same-culture loans being on average significantly better performing than different-culture loans. These findings confirm our hypothesis that cultural proximity mitigates information asymmetries: sharing the

\footnotetext{
${ }^{19}$ We use a three-year moving window because banks usually employ three years to actually report in their balance sheet a loan as non-performing.
} 
same cultural background helps banks gather additional information upon their perspective borrowers. This translates into a better screening of firms, leading to significantly better loan outcomes.

\section{Conclusions}

In this paper, we explore the mechanisms behind the formation of lending relationships in which firms and banks share the same cultural background, and on the quality of resulting loans. We construct a comprehensive dataset that traces all bank-firm relationships for the population of firms and banks that operate in South Tyrol, a region located in Northern Italy. For each bank and firm, we link all available information on the board members. Using an algorithm that is able to link names and surnames to linguistic groups (Grinblatt and Keloharju, 2001), we are able to attribute a predominant cultural group in the boards of banks and firms.

We document that the proportion of loans between banks and firms that share a cultural origin is twice as large as the one implied by random matching between firms and banks given their presence in the local markets. This correlation suggests that there is a strong selection in lending relationships where borrowers and lenders share similar cultural endowments.

We advance two main hypotheses to explain this stylized fact. Our first hypothesis is that cultural proximity overcomes frictions in the credit markets, such as information asymmetries (information hypothesis). Our second hypothesis to explain the prevalence of culturally proximate lending relationships is that borrowers expect a more favorable treatment from lenders which might belong, or be close to, their social network (favoritism hypothesis).

We find strong support for the information hypothesis, both in the analysis of the demand side and the supply of credit.

Young startups, small firms, and high growth firms are more likely to apply for loan to banks from their same cultural background. Moreover, the demand for loans from culturally 
proximate banks decreases sharply with size and age, suggesting that borrowers rely on cultural proximity mostly when their levels of opaqueness are highest.

Results from the analysis on the supply side of credit also confirm the information hypothesis: lenders are not more likely to approve a loan application from culturally proximate borrowers. We also observe larger dispersion in the terms of loans provided to culturally proximate borrowers. Our final analysis shows that the loans lent to culturally proximate borrowers are significantly less likely to become non-performing.

Combined with the results that show lower collateral requirements and higher loan amounts for culturally proximate loans, this finding suggests that the mechanism through which cultural proximity reduces information asymmetries is by facilitating loan applications' screening process.

To the best of our knowledge, ours is the first study to analyze the role of cultural proximity in the formation of lending relationships in greater detail, by decomposing the credit process into the loan application phase (demand for credit), the credit screening process (supply of credit), and the lending outcomes (ex-post performance). Our paper shows that cultural proximity reduces the information asymmetries in the credit transaction by improving the precision of the signal that the lender obtains about the borrower's creditworthiness.

Finally, our findings also highlight the importance of local banks in lending to small businesses. By sharing the same culture as the firms in the markets where they operate, these financial intermediaries may play a key role in promoting access to credit, particularly for more informationally-opaque firms. 


\section{References}

Accetturo, A., Cascarano, M., Degasperi, P., and Modena, F. The effects of common culture and language on economic exchanges: Evidence from tourist flows. Regional Studies, 53 (11):1575-1590, 2019.

Ahern, K. R., Daminelli, D., and Fracassi, C. Lost in translation? the effect of cultural values on mergers around the world. Journal of Financial Economics, 117(1):165-189, 2015.

Albertazzi, U., Bottero, M., and Sene, G. Information externalities in the credit market and the spell of credit rationing. Journal of Financial Intermediation, 30:61-70, 2017.

Angelini, P., Di Salvo, R., and Ferri, G. Availability and cost of credit for small businesses: customer relationships and credit cooperatives. Journal of Banking \& Finance, 22(6-8): 925-954, 1998.

Barboni, G. and Rossi, C. Does your neighbour know you better? the supportive role of local banks in the financial crisis. Journal of Banking \& Finance, 106:514-526, 2019.

Bedendo, M., Garcia-Appendini, E., and Siming, L. Cultural preferences and firm financing choices. Journal of Financial and Quantitative Analysis, pages 1-34, 2018.

Benvenuti, M., Casolaro, L., Del Prete, S., and Mistrulli, P. E. The right to decide and the effective control over small business lending decisions: A look into loan officers' real authority. Economic Notes: Review of Banking, Finance and Monetary Economics, 46(2): 237-268, 2017.

Berger, A. N. and Udell, G. F. Collateral, loan quality and bank risk. Journal of Monetary Economics, 25(1):21-42, 1990.

Berger, A. N. and Udell, G. F. The economics of small business finance: The roles of private 
equity and debt markets in the financial growth cycle. Journal of Banking \& Finance, 22 (6-8):613-673, 1998.

Berger, A. N. and Udell, G. F. Small business credit availability and relationship lending: The importance of bank organisational structure. The Economic Journal, 112(477):F32-F53, 2002.

Berger, A. N., Udell, G. F., et al. Relationship lending and lines of credit in small firm finance. The Journal of Business, 68(3):351-381, 1995.

Bester, H. Screening vs. rationing in credit markets with imperfect information. The American economic review, 75(4):850-855, 1985.

Bottazzi, L., Da Rin, M., and Hellmann, T. The importance of trust for investment: Evidence from venture capital. The Review of Financial Studies, 29(9):2283-2318, 2016.

Branzoli, N. and Fringuellotti, F. The effect of bank monitoring on loan repayment. FRB of New York Staff Report, (923), 2020.

Chan, Y.-S. and Kanatas, G. Asymmetric valuations and the role of collateral in loan agreements. Journal of money, credit and banking, 17(1):84-95, 1985.

Cingano, F., Manaresi, F., and Sette, E. Does credit crunch investment down? New evidence on the real effects of the bank-lending channel. The Review of Financial Studies, 29(10): $2737-2773,2016$.

Cornell, B. and Welch, I. Culture, information, and screening discrimination. Journal of Political Economy, 104(3):542-571, 1996.

Degryse, H. and Ongena, S. Distance, lending relationships, and competition. The Journal of Finance, 60(1):231-266, 2005. 
Degryse, H., De Jonghe, O., Jakovljević, S., Mulier, K., and Schepens, G. Identifying credit supply shocks with bank-firm data: Methods and applications. Journal of Financial Intermediation, 40:100813, 2019.

Dennis, S., Nandy, D., and Sharpe, I. G. The determinants of contract terms in bank revolving credit agreements. Journal of financial and quantitative analysis, pages 87-110, 2000.

Diamond, D. W. Seniority and maturity of debt contracts. Journal of financial Economics, 33(3):341-368, 1993.

Diamond, D. W. and Rajan, R. G. Liquidity risk, liquidity creation, and financial fragility: A theory of banking. Journal of Political Economy, 109(2):287-327, 2001.

Disdier, A.-C. and Mayer, T. Je t'aime, moi non plus: Bilateral opinions and international trade. European Journal of Political Economy, 23(4):1140-1159, 2007.

Fernández, R. Does culture matter? In Handbook of Social Economics, volume 1, pages 481-510. Elsevier, 2011.

Fisman, R., Paravisini, D., and Vig, V. Cultural proximity and loan outcomes. The American Economic Review, 107(2):457-92, 2017.

Forer, D., Paladino, M., Vettori, C., and Abel, A. Il bilinguismo in alto adige: Percezioni, osservazioni e opinioni su una questione quanto mai aperta. Il Cristallo-Rassegna di Varia Umanità, 50(1):49-62, 2008.

Giannetti, M. and Yafeh, Y. Do cultural differences between contracting parties matter? Evidence from syndicated bank loans. Management Science, 58(2):365-383, 2012.

Grinblatt, M. and Keloharju, M. How distance, language, and culture influence stockholdings and trades. The Journal of Finance, 56(3):1053-1073, 2001. 
Guiso, L., Sapienza, P., and Zingales, L. Cultural biases in economic exchange? The Quarterly Journal of Economics, 124(3):1095-1131, 2009.

Haselmann, R., Schoenherr, D., and Vig, V. Rent seeking in elite networks. Journal of Political Economy, 126(4):1638-1690, 2018.

Heckman, J. J., Urzua, S., and Vytlacil, E. Understanding instrumental variables in models with essential heterogeneity. The Review of Economics and Statistics, 88(3):389-432, 2006.

Helpman, E., Melitz, M., and Rubinstein, Y. Estimating trade flows: Trading partners and trading volumes. The Quarterly Journal of Economics, 123(2):441-487, 2008.

Inderst, R. and Mueller, H. M. A lender-based theory of collateral. Journal of Financial Economics, 84(3):826-859, 2007.

Infante, L. and Piazza, M. Political connections and preferential lending at local level: Some evidence from the italian credit market. Journal of Corporate Finance, 29:246-262, 2014.

Khwaja, A. I. and Mian, A. Tracing the impact of bank liquidity shocks: Evidence from an emerging market. The American Economic Review, 98(4):1413-42, 2008.

Melitz, J. Language and foreign trade. European Economic Review, 52(4):667-699, 2008.

Petersen, M. and Rajan, R. G. Does distance still matter? The information revolution in small business lending. The Journal of Finance, 57(6):2533-2570, 2002.

Petersen, M. A. and Rajan, R. G. The effect of credit market competition on lending relationships. The Quarterly Journal of Economics, 110(2):407-443, 1995.

Rose, A. K. One money, one market: The effect of common currencies on trade. Economic Policy, 15(30):08-45, 2000. 
Strahan, P. E. Borrower risk and the price and nonprice terms of bank loans. FRB of New York staff report, (90), 1999.

Tabellini, G. Institutions and culture. Journal of the European Economic association, 6(2-3): 255-294, 2008.

Vettori, C. and Abel, A. Gli studenti altoatesini e la seconda lingua: Indagine linguistica e psicosociale. Die Südtiroler Schülerinnen und die Zweitsprache: Eine linguistische und sozialpsychologische Untersuchung. Eurac Research, 2017. 


\section{$7 \quad$ Figures and Tables}

Figure 1: Geographic distribution of linguistic groups in South Tyrol.

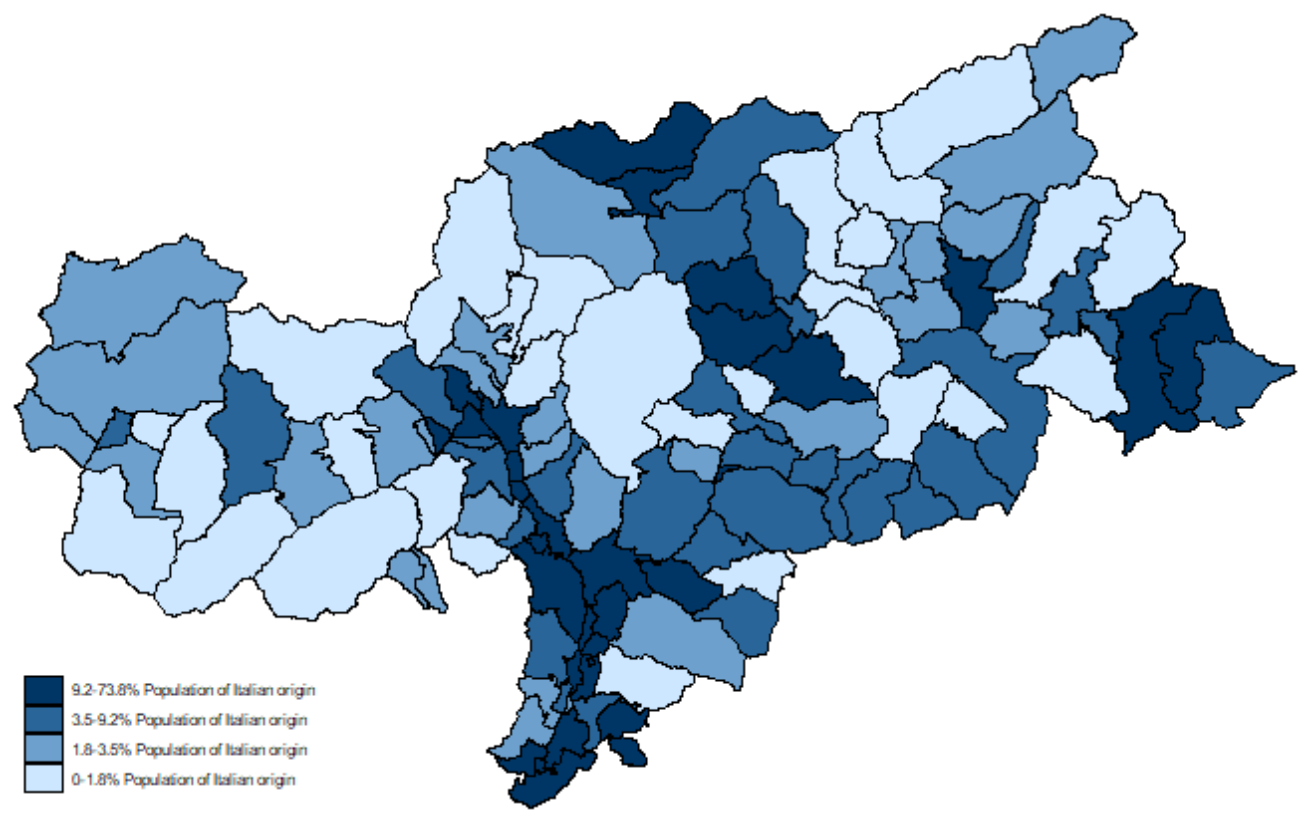

Note: This figure shows the distribution (quartiles) of the Italian-speaking population by municipality in the South Tyrol, as reported by the 2011 Census (Istituto Provinciale di Statistica, 2015).

Table 1: Descriptive statistics: Sample distribution

\begin{tabular}{lcccc}
\hline & $\begin{array}{c}\text { No. of } \\
\text { unique firms }\end{array}$ & $\begin{array}{c}\text { No. of } \\
\text { unique banks }\end{array}$ & $\begin{array}{c}\text { Share of } \\
\text { Italian firms }\end{array}$ & $\begin{array}{c}\text { Share of } \\
\text { Italian banks }\end{array}$ \\
\hline 2005 & 8213 & 174 & 0.25 & 0.672 \\
2006 & 8503 & 189 & 0.248 & 0.693 \\
2007 & 8693 & 197 & 0.249 & 0.695 \\
2008 & 8728 & 208 & 0.244 & 0.712 \\
2009 & 8413 & 217 & 0.243 & 0.737 \\
2010 & 8409 & 225 & 0.241 & 0.751 \\
2011 & 8258 & 223 & 0.236 & 0.749 \\
2012 & 8019 & 226 & 0.231 & 0.757 \\
2013 & 8046 & 222 & 0.232 & 0.739 \\
2014 & 8134 & 219 & 0.233 & 0.744 \\
2015 & 8150 & 224 & 0.233 & 0.754 \\
Total & 13469 & 361 & 0.233 & 0.754 \\
\hline
\end{tabular}

Notes: This table contains a description of the number of firms and banks in our sample across the years, and their distribution across cultural groups. Authors' calculation on CR-Or.So.-Infocamere-INPS dataset. 
Table 2: Descriptive statistics: Firm, bank \& loan characteristics

\begin{tabular}{lcccccc}
\hline & No. Obs. & Mean & St. dev. & p25 & p50 & p75 \\
\hline Firm characteristics & & & & & & \\
Age (years) & 91,190 & 15.584 & 13.386 & 6.000 & 13.000 & 23.000 \\
No. of employees & 64,851 & 17.456 & 143.986 & 2.333 & 5.500 & 12.167 \\
Multi-borrowing & 91,182 & 0.317 & 0.465 & 0 & 0 & 1.000 \\
Bank links & 91,182 & 1.573 & 1.353 & 1.000 & 1.000 & 2.000 \\
Bank links in same group & 91,182 & 1.143 & 1.096 & 1.000 & 1.000 & 1.000 \\
Bank characteristics & & & & & & \\
BCC & 2,336 & 0.480 & 0.500 & 0 & 0 & 1.000 \\
log(Total assets) & 1,913 & 20.939 & 2.027 & 19.354 & 20.708 & 22.450 \\
Total assets to capital ratio & 1,913 & 11.979 & 8.743 & 7.456 & 10.111 & 13.637 \\
NPL ratio & 1,902 & 0.112 & 0.074 & 0.058 & 0.094 & 0.147 \\
Loan characteristics & & & & & & \\
Same group & 143,422 & 0.727 & 0.446 & 0 & 1.000 & 1.000 \\
Nearby branch & 143,594 & 0.732 & 0.443 & 0 & 1.000 & 1.000 \\
log(1+Length of relationship) & 143,594 & 1.861 & 0.837 & 1.386 & 2.079 & 2.485 \\
log(granted loans) & 143,594 & 13.041 & 1.251 & 12.005 & 12.862 & 13.856 \\
Collateral & 143,594 & 0.320 & 0.467 & 0 & 0 & 1.000 \\
NPL & 133,807 & 0.101 & 0.301 & 0 & 0 & 0 \\
Minor anomalies & 133,807 & 0.087 & 0.282 & 0 & 0 & 0 \\
\hline
\end{tabular}

Notes: This table contains summary statistics for the main variables used in our analysis. The sample consists of all firm-bank-year observations for firms in the South Tyrol Region appearing in the credit registry between years 2005 and 2015. To calculate firm characteristics, we use a single observation per firm and year. Multiborrowing is a dummy variable equal to one if the firm has multiple banking relationships. Bank links is the total number of bank relationships established by the firm during the year. Bank links in the same group is the total number of relationships with banks of the same cultural group established by the firm during the year. To calculate bank characteristics, we use a single observation per bank and year. $B C C$ is a dummy variable taking a one if the bank is a credit cooperative, Banca di Credito Cooperativo (BCC). $\log$ (Total assets) is the natural logarithm of total bank assets. Total assets to capital ratio is the ratio between total bank assets and total capital. NPL ratio is the ratio of non performing loans (NPLs) to total loans. Same group is a dummy variable taking a one if the bank and the firm belong to the same cultural group, and zero otherwise. Nearby branch is an indicator variable for the existence of a bank branch in the same municipality as the firm. $\log (1+$ length of relationship $)$ corresponds to the natural logarithm of one plus the length of the bank-firm relationship, measured in years since 1997. $\log$ (granted loans) corresponds to the natural logarithm of the total amount of loans granted by the bank to the firm in each year. Collateral is a dummy taking the value of one if the loans were collateralized, zero otherwise. NPL is a dummy taking a value one if the loan is classified as non-performing, zero otherwise. Minor anomalies is a dummy taking value one if the loan is classified as unlikely to pay. Authors' calculation on CR-Or.So.-Infocamere-INPS dataset. 


\section{Table 3: Firm characteristics: Borrowing from banks of same vs different culture}

\begin{tabular}{lccc|ccc|c}
\hline Variable & \multicolumn{3}{c|}{$\begin{array}{c}\text { All loans from a bank } \\
\text { of same culture }\end{array}$} & \multicolumn{3}{|c|}{$\begin{array}{c}\text { At least one loan with } \\
\text { a bank of different culture }\end{array}$} & p-value \\
& $\begin{array}{c}\text { Mean } \\
(1)\end{array}$ & St. dev. & $\mathrm{N}$ & Mean & St. dev. & $\mathrm{N}$ & \\
& $(2)$ & $(3)$ & $(4)$ & $(5)$ & $(6)$ & $(7)$ \\
Age & 15.395 & 13.563 & 62,749 & 16.004 & 12.976 & 28,433 & 0.000 \\
Size & 9.696 & 15.658 & 44,295 & 18.028 & 31.124 & 20,555 & 0.000 \\
Growth & 0.135 & 0.795 & 42,741 & 0.123 & 0.774 & 19,823 & 0.085 \\
\# bank links & 1.327 & 0.967 & 62,749 & 2.114 & 1.838 & 28,433 & 0.000 \\
Rel. length & 7.557 & 4.906 & 62,749 & 6.954 & 4.515 & 28433 & 0.000 \\
\hline
\end{tabular}

Notes: The sample corresponds to firm-year observations of firms headquartered in the South Tyrol region and included in the Italian credit registry between years 2005 and 2015. Firms are classified into those that establish relationships only with banks of their same group (columns 1-3) and those that establish relationships at least with one bank of a different cultural group (columns 4-6). The p-value for the univariate test of difference in means is contained in the last column. Age is measured in years. Size is the natural logarithm of the number of employees. Growth corresponds to the yearly sales growth rate. \# bank links corresponds to the total number of banks lending to the firm in each year. Rel. length corresponds to the average, across all banks lending to the firm in a given year, of the length of the relationship between the firm and the bank (number of years since 1997). Source: Authors' calculation on CR-Or.So.-Infocamere-INPS dataset. 


\section{Table 4: Bank characteristics: Lending to firms of same vs different culture}

\begin{tabular}{|c|c|c|c|c|c|c|c|}
\hline \multirow[t]{2}{*}{ Variable } & \multicolumn{3}{|c|}{$\begin{array}{l}\text { Share of firms } \\
\text { of same group } \\
\text { above the median }\end{array}$} & \multicolumn{3}{|c|}{$\begin{array}{l}\text { Share of firms } \\
\text { of same group } \\
\text { below the median }\end{array}$} & \multirow{2}{*}{$\begin{array}{c}\text { p-value } \\
(7)\end{array}$} \\
\hline & $\begin{array}{c}\text { Mean } \\
(1)\end{array}$ & $\begin{array}{c}\text { St. dev. } \\
(2)\end{array}$ & $\begin{array}{l}\mathrm{N} \\
(3)\end{array}$ & $\begin{array}{l}\text { Mean } \\
(4)\end{array}$ & $\begin{array}{l}\text { St. dev. } \\
(5)\end{array}$ & $\begin{array}{l}\mathrm{N} \\
(6)\end{array}$ & \\
\hline Different group & 0.024 & 0.048 & 1,15 & 0.633 & 0.283 & 1,146 & 0.000 \\
\hline $\mathrm{BCC}$ & 0.652 & 0.477 & 1,155 & 0.312 & 0.464 & 1,181 & 0.000 \\
\hline Total assets & 20.072 & 1.579 & 990 & 21.868 & 2.044 & 923 & 0.000 \\
\hline Total capital & 17.857 & 1.364 & 990 & 19.394 & 1.819 & 923 & 0.000 \\
\hline Capital ratio & 0.119 & 0.052 & 990 & 0.095 & 0.048 & 923 & 0.000 \\
\hline NPL ratio & 0.109 & 0.070 & 981 & 0.115 & 0.079 & 921 & 0.096 \\
\hline
\end{tabular}

Notes: The sample corresponds to bank-year observations of banks lending to firms located in the South Tyrol region and included in the Italian credit registry between years 2005 and 2015. Banks are classified into those that lend to a share of firms of the same cultural group that is above (columns 1-3) or below the yearly median (columns 4-6). The p-value for the univariate test of difference in means of each variable is contained in the last column. Different group is the share of firms from a different cultural group borrowing from the bank. $B C C$ is a dummy variable equal to one for cooperative banks Banca di Credito Cooperativo (BCC). Total assets is the natural logarithm of total bank assets. Total capital is the natural logarithm of total bank capital. Capital ratio is the ratio of total capital to total assets. NPL ratio is the ratio of non-performing loans (NPL) to total loans. Source: Authors' calculation on CR-Or.So.-Infocamere-INPS dataset. 
Table 5: Cultural proximity and the demand for new relationships

\begin{tabular}{lccccc}
\hline \multicolumn{1}{c}{$(1)$} & $(2)$ & $(3)$ & $(4)$ & $(5)$ \\
\hline Same group & $\begin{array}{c}0.00562^{* * *} \\
(27.56)\end{array}$ & $\begin{array}{c}0.00515^{* * *} \\
(27.70)\end{array}$ & $\begin{array}{c}0.00620^{* * *} \\
(28.22)\end{array}$ & $\begin{array}{c}0.00755^{* * *} \\
(27.41)\end{array}$ & $\begin{array}{c}0.00588^{* * *} \\
(26.97) \\
\text { Nearby branch }\end{array}$ \\
& & & & $\begin{array}{c}0.0323^{* * *} \\
(39.43)\end{array}$ \\
& & & & \\
Adj. $R^{2}$ & 0.001 & 0.095 & 0.094 & 0.092 & 0.098 \\
No. Obs. & 2710594 & 2710594 & 2710594 & 2710594 & 2710594 \\
Dep. Var. Mean & 0.0145 & 0.0145 & 0.0145 & 0.0145 & 0.0145 \\
\hline Fixed effects: & & & & & \\
Year & $\checkmark$ & & $\checkmark$ & $\checkmark$ & $\checkmark$ \\
Bank-Year & & $\checkmark$ & $\checkmark$ & $\checkmark$ & $\checkmark$ \\
Ind-Size-Age-Loc-Yr & & & & $\checkmark$ & \\
Firm-Year & & & & & \\
\hline
\end{tabular}

Notes: The sample consists of all firm-bank-pairs where the firm is located in the South Tyrol and the bank has a branch operating in the same local labor market as the firm between years 2005 and 2015. The dependent variable is LoanApplication, a dummy variable taking the value one if the bank lodged a request of information from the firm (as recorded in the SPI database), and zero otherwise. Same group is a dummy that equals one if the firm and the bank share the same cultural origin. Nearby branch is an indicator variable for the existence of a bank branch in the same municipality as the firm. For the fixed effects: Ind are 201 firm sector groups; Size (Age) are 4 equally-sized size (age) bins; Loc are indicators for 14 local labor markets. T-stats are in parenthesis. ${ }^{*},{ }^{*},{ }^{* *}$ denotes significance at the $10 \% ; 5 \% ; 1 \%$ level, respectively. Standard errors clustered at bank-firm level. 


\section{Table 6: Cultural proximity and information asymmetries}

\begin{tabular}{|c|c|c|c|c|}
\hline & $(1)$ & $(2)$ & $(3)$ & $(4)$ \\
\hline Same group (SG) & $\begin{array}{c}0.0105^{* * *} \\
(17.39)\end{array}$ & $\begin{array}{c}0.0112^{* * *} \\
(25.02)\end{array}$ & $\begin{array}{c}0.0141^{* * *} \\
(14.66)\end{array}$ & $\begin{array}{c}0.0131^{* * *} \\
(11.56)\end{array}$ \\
\hline Age & $\begin{array}{c}0.000928^{* * *} \\
(5.432)\end{array}$ & & $\begin{array}{c}-0.000657^{* * *} \\
(-2.585)\end{array}$ & $\begin{array}{c}-0.000720^{* *} \\
(-2.542)\end{array}$ \\
\hline $\mathrm{SG} \times$ Age & $\begin{array}{c}-0.00217^{* * *} \\
(-8.811)\end{array}$ & & $\begin{array}{c}-0.00124^{* * *} \\
(-3.286)\end{array}$ & $\begin{array}{c}-0.000479 \\
(-1.142)\end{array}$ \\
\hline Size & & $\begin{array}{c}0.00234^{* * *} \\
(17.87)\end{array}$ & $\begin{array}{c}0.00242^{* * * *} \\
(17.93)\end{array}$ & $\begin{array}{c}0.00270^{* * *} \\
(18.14)\end{array}$ \\
\hline $\mathrm{SG} \times$ Size & & $\begin{array}{c}-0.00308^{* * *} \\
(-15.71)\end{array}$ & $\begin{array}{c}-0.00296^{* * *} \\
(-14.65)\end{array}$ & $\begin{array}{c}-0.00336^{* * *} \\
(-15.17)\end{array}$ \\
\hline Growth & & & & $\begin{array}{l}0.0000 \\
(0.190)\end{array}$ \\
\hline $\mathrm{SG} \times$ Growth & & & & $\begin{array}{c}0.000599^{* * *} \\
(2.676)\end{array}$ \\
\hline Nearby branch & $\begin{array}{c}0.0317^{* * *} \\
(38.95)\end{array}$ & $\begin{array}{c}0.0318^{* * *} \\
(28.47)\end{array}$ & $\begin{array}{c}0.0318^{* * *} \\
(28.46)\end{array}$ & $\begin{array}{c}0.0302^{* * *} \\
(25.86)\end{array}$ \\
\hline Adjusted $R^{2}$ & 0.099 & 0.090 & 0.090 & 0.088 \\
\hline No. Obs. & 2710594 & 1389694 & 1389694 & 1270239 \\
\hline Dep. Var. Mean & 0.0145 & 0.0160 & 0.0160 & 0.0159 \\
\hline Fixed effects: & & & & \\
\hline Industry-Location-Year & $\checkmark$ & $\checkmark$ & $\checkmark$ & $\checkmark$ \\
\hline Bank-Year & $\checkmark$ & $\checkmark$ & $\checkmark$ & $\checkmark$ \\
\hline
\end{tabular}

Notes: The sample consists of all firm-bank-pairs where the firm is located in the South Tyrol and the bank has a branch operating in the same local labor market as the firm between years 2005 and 2015. The dependent variable is LoanApplication, a dummy variable equal to one if the bank lodged a request of new information form the firm, and zero otherwise. Age represents the years of activity. Size is the natural logarithm of the number of employees. Growth corresponds to the yearly sales growth rate. Same group is a dummy that equals one if the firm and the bank share the same cultural origin. Nearby branch is an indicator variable for the existence of a bank branch in the same municipality as the firm. For the fixed effects: Industry are 201 firm sector groups and Location are indicators for 14 local labor markets. All other independent variables are defined in Table 3. T-stats are in parenthesis. ${ }^{*},{ }^{* *},{ }^{* * *}$ denotes significance at the $10 \% ; 5 \% ; 1 \%$ level, respectively. Standard errors clustered at the bank-firm level. 
Figure 2: Firm age and demand for loans from a new bank

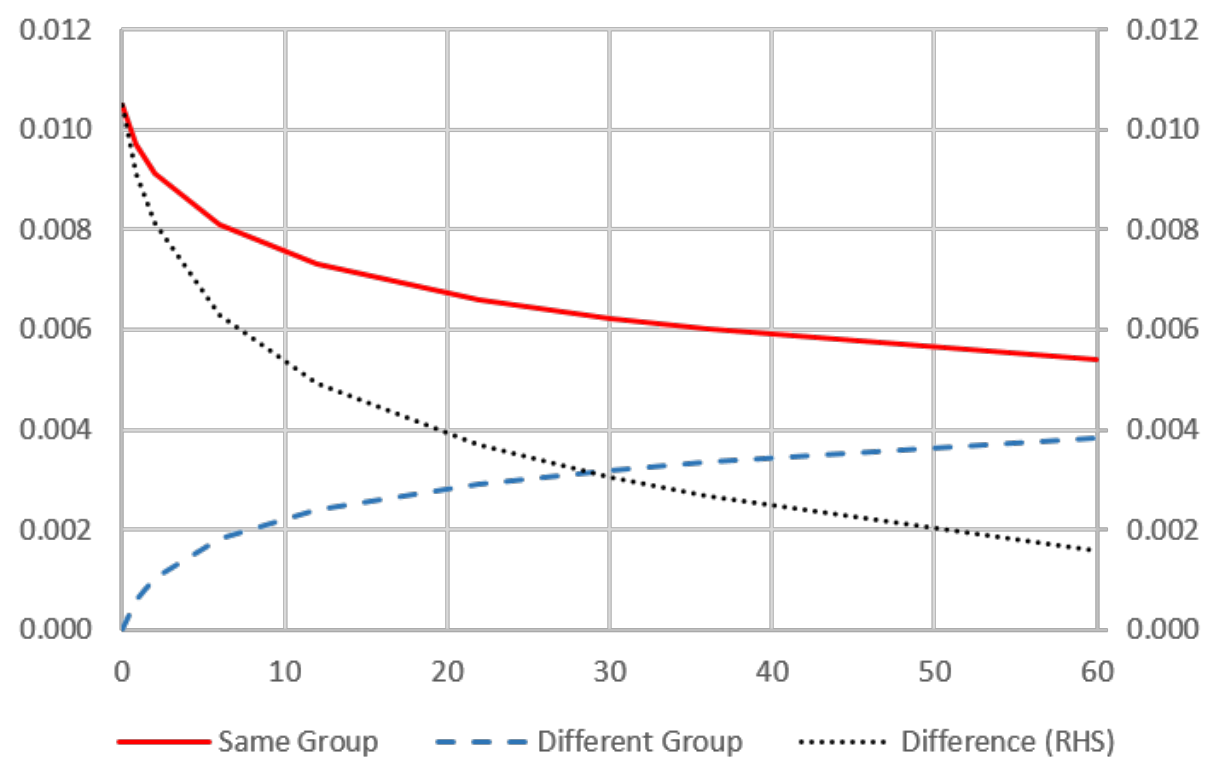

This figure shows the marginal effect of firm age on the demand for new loans from a bank of the same cultural group (solid red line) or from a bank from a different cultural group (broken blue line). The difference is represented by the dotted line. Estimated coefficients correspond to column 1 of Table 6 .

\section{Figure 3: Firm size and demand for loans from a new bank}

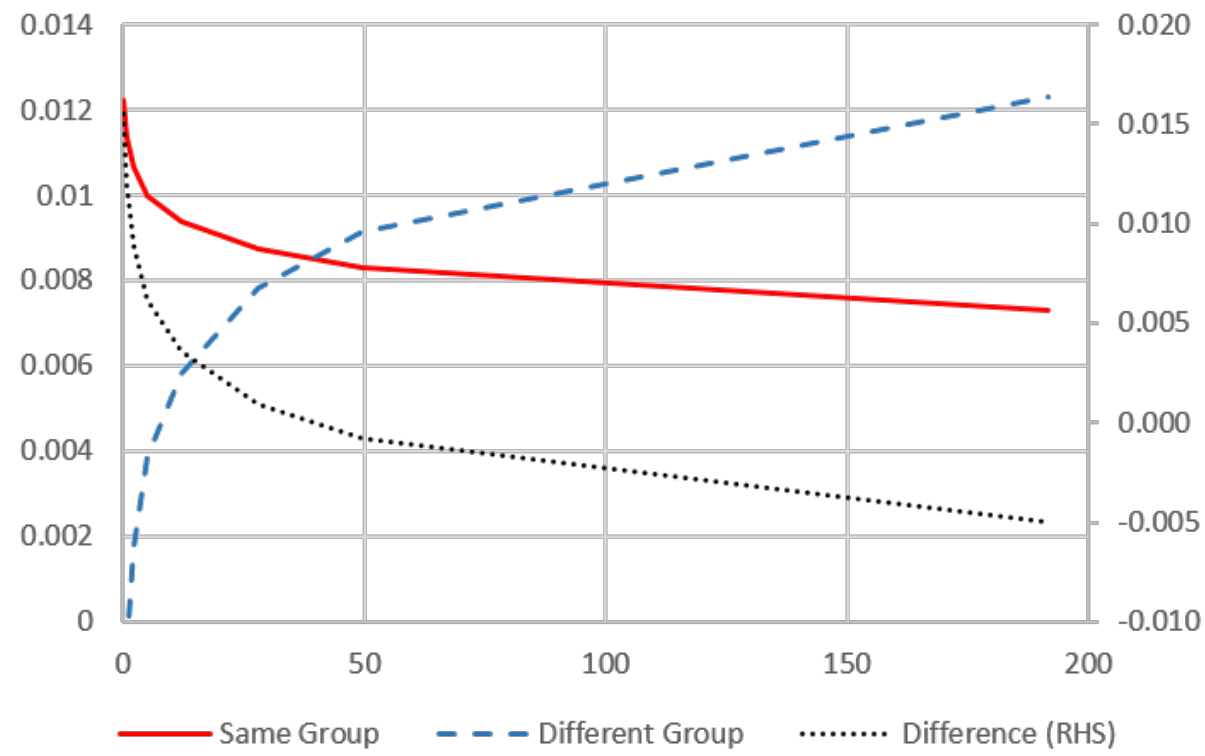

This figure shows the marginal effect of firm size (number of employees) on the demand for new loans from a bank of the same cultural group (solid red line) or from a bank from a different cultural group (broken blue line). The difference is represented by the dotted line. Estimated coefficients correspond to column 2 of Table 6. 


\section{Table 7: Cultural proximity and credit supply}

\begin{tabular}{|c|c|c|c|c|c|}
\hline & (1) & $(2)$ & $(3)$ & $(4)$ & $(5)$ \\
\hline \multirow[t]{2}{*}{ Same group } & $0.0390^{* * *}$ & -0.00337 & $-0.0114^{*}$ & 0.000702 & 0.0110 \\
\hline & $(7.507)$ & $(0.613)$ & $(1.710)$ & $(0.0540)$ & $1.645)$ \\
\hline \multirow[t]{2}{*}{ Nearby branch } & & & & & -0.0107 \\
\hline & & & & & $(1.332)$ \\
\hline Adj. $R^{2}$ & 0.005 & 0.100 & 0.162 & 0.192 & 0.162 \\
\hline No. Obs. & 31,190 & 30,830 & 25,613 & 11,662 & 25,613 \\
\hline Dep. Var. Mean & 0.229 & 0.226 & 0.226 & 0.229 & 0.226 \\
\hline \multicolumn{6}{|l|}{ Fixed effects: } \\
\hline Year & $\checkmark$ & & & & \\
\hline & $\checkmark$ & $\checkmark$ & $\checkmark$ & $\checkmark$ \\
\hline \multicolumn{2}{|c|}{ Ind-Size-Age-Loc-Yr } & & $\checkmark$ & & $\checkmark$ \\
\hline \multicolumn{2}{|c|}{ Firm-Year } & & & $\checkmark$ & \\
\hline
\end{tabular}

Notes: This table shows OLS estimates for Equation 2. The sample consists of firms-bank-year observations in the SPI dataset, indicating loan applications by firms to banks with which they had no prior relationship. The dependent variable is LoanApproval ${ }_{i j t}$, a dummy that equals one if firm $i$ has an outstanding credit relationship appearing in the credit registry with the bank in year $t$. Same group is a dummy that equals one if the firm and the bank share the same cultural origin. Nearby branch is an indicator variable for the existence of a bank branch in the same municipality as the firm. For the fixed effects: Ind are 201 firm sector groups; Size (Age) are 20 equally-sized size (age) bins; Loc are indicators for 14 local labor markets. T-stat are in parenthesis. ${ }^{*}, * *, * * *$ denotes significance at the $10 \% ; 5 \% ; 1 \%$ level, respectively. Standard errors clustered at bank-firm level 
Table 8: Cultural proximity and loan terms

\begin{tabular}{lccccc}
\hline & $(1)$ & $(2)$ & $(3)$ & $(4)$ & $(5)$ \\
\hline \multicolumn{1}{c}{ Panel A: Loan size } & & & & \\
\hline Same group & -0.0129 & $0.0549^{* * *}$ & $0.0381^{* *}$ & $0.0419^{*}$ & $0.0319^{*}$ \\
& $(0.688)$ & $(2.769)$ & $(1.980)$ & $(1.701)$ & $(1.664)$ \\
Nearby branch & & & & $0.0466^{* *}$ \\
& & & & & $(2.187)$ \\
Length relationship & & & & $0.134^{* * *}$ \\
& & & & & $(12.75)$ \\
Adj. $R^{2}$ & 0.002 & 0.065 & 0.321 & 0.474 & 0.325 \\
No. Obs & 143,422 & 142,685 & 126,698 & 80,299 & 126,698 \\
\hline
\end{tabular}

\section{Panel B: Loan maturity}

\begin{tabular}{|c|c|c|c|c|c|}
\hline Same group & $\begin{array}{c}-0.0330^{* * *} \\
(5.610)\end{array}$ & $\begin{array}{c}-0.00168 \\
(0.275)\end{array}$ & $\begin{array}{c}-0.00667 \\
(1.084)\end{array}$ & $\begin{array}{c}0.00290 \\
(0.368)\end{array}$ & $\begin{array}{c}-0.00481 \\
(0.784)\end{array}$ \\
\hline Nearby branch & & & & & $\begin{array}{c}-0.0204^{* * *} \\
(3.022)\end{array}$ \\
\hline Length relationship & & & & & $\begin{array}{c}-0.0391^{* * *} \\
(11.22)\end{array}$ \\
\hline Adj. $R^{2}$ & 0.010 & 0.121 & 0.278 & 0.403 & 0.282 \\
\hline No. Obs & 143,422 & 142,685 & 126,698 & 80,299 & 126,698 \\
\hline \multicolumn{6}{|c|}{ Panel C: Collateral } \\
\hline Same group & $\begin{array}{c}0.0198^{* * *} \\
(2.867)\end{array}$ & $\begin{array}{c}-0.0234^{* * *} \\
(3.113)\end{array}$ & $\begin{array}{c}-0.0131^{*} \\
(1.742)\end{array}$ & $\begin{array}{c}0.00155 \\
(0.170)\end{array}$ & $\begin{array}{c}-0.0150^{* *} \\
(1.986)\end{array}$ \\
\hline Nearby branch & & & & & $\begin{array}{c}-0.0225^{* * *} \\
(2.714)\end{array}$ \\
\hline Length relationship & & & & & $\begin{array}{c}0.0454^{* * *} \\
(11.30)\end{array}$ \\
\hline Adj. $R^{2}$ & 0.007 & 0.054 & 0.214 & 0.392 & 0.218 \\
\hline No. Obs. & 143,422 & 142,685 & 126,698 & 80,299 & 126,698 \\
\hline
\end{tabular}

Fixed effects:

\begin{tabular}{|c|c|c|c|c|}
\hline Year & & & & \\
\hline Bank-Year & $\checkmark$ & $\checkmark$ & $\checkmark$ & $\checkmark$ \\
\hline Ind-Size-Age-Loc-Yr & & $\checkmark$ & & $\checkmark$ \\
\hline Firm-Year & & & $\checkmark$ & \\
\hline
\end{tabular}

Notes: This table shows OLS estimates for Equation 2. The sample consists of firms-bank-year observations for firms located in the South Tyrol Region appearing in the Italian credit registry between 2005 and 2015. The dependent variables are: the log of credit volume granted (Panel A; average =13.04); the fraction of loans provided that are long-term (Panel B; average $=0.414)$; and a dummy variable equal to one if at least one of the loans were required to post collateral (Panel C; average $=0.321$ ). All independent variables are defined in Table 7. T-stat are in parenthesis. ${ }^{*},{ }^{* *},{ }^{* * *}$ denotes significance at the $10 \% ; 5 \% ; 1 \%$ level, respectively. Standard errors clustered at bank-firm level 
Table 9: Cultural proximity and dispersion in loan terms

\begin{tabular}{lcccccc}
\hline & $(1)$ & $(2)$ & $(3)$ & $(4)$ & $(5)$ & $(6)$ \\
Dependent variable: & $\sigma($ LoanSize $)$ & $\sigma($ Maturity $)$ & $\sigma($ Collateral $)$ \\
\hline & & & & & & \\
Same group & $0.112^{* * *}$ & $0.115^{* * *}$ & $0.0276^{* * *}$ & $0.0257^{* * *}$ & $0.0221^{* * *}$ & $0.0203^{* * *}$ \\
& $(6.093)$ & $(6.108)$ & $(3.768)$ & $(3.391)$ & $(3.237)$ & $(2.898)$ \\
Nearby branch (avg.) & & -0.0767 & & $0.0524^{*}$ & & $0.0473^{* *}$ \\
& & $(1.560)$ & & $(1.781)$ & & $(1.979)$ \\
Length Relationship (avg.) & & -0.0103 & & -0.00387 & & 0.00256 \\
& & $(0.312)$ & & $(0.306)$ & & $(0.196)$ \\
Adj. $R^{2}$ & & & & & & \\
No. Obs & 0.473 & 0.473 & 0.549 & 0.549 & 0.551 & 0.552 \\
Dep. Var. Mean & 2,243 & 2,243 & 2,243 & 2,243 & 2,243 & 2,243 \\
& 1.288 & 1.288 & 0.348 & 0.348 & 0.393 & 0.393 \\
Bank fixed effects & & & & & & $\checkmark$ \\
Year fixed effects & $\checkmark$ & $\checkmark$ & $\checkmark$ & $\checkmark$ & $\checkmark$ & $\checkmark$ \\
\hline
\end{tabular}

Notes: To construct the sample for this table, we collapse the CR database to obtain summary statistics of the borrowers of each bank and year, for two categories of borrowers: those in the same and in a different cultural group as the bank. The dependent variable is the standard deviation in: loan size, measured as the log of credit volume granted (columns 1 and 2); loan maturity, measured as the fraction of long-term debt provided (columns 3 and 4); and collateral requirements, measured with a dummy variable if the loan is collateralized (columns 5 and 6). Same group is a dummy indicating with the value one when the summary statistics refer to borrowers of the same cultural group as the bank, and zero for borrowers of a different cultural group. Nearby branch (avg.) and Length relationship (avg.) are, respectively, the fraction of borrowers that are in close vicinity to the bank and the average length of the relationship between the borrowers and the bank (measured in $\log$ years). T-stats are in parenthesis. ${ }^{*},{ }^{*},{ }^{* * *}$ denotes significance at the $10 \% ; 5 \% ; 1 \%$ level, respectively. 
Table 10: Loan performance

\begin{tabular}{lccccc}
\hline \multicolumn{7}{c}{$(1)$} & $(2)$ & $(3)$ & $(4)$ & $(5)$ \\
\hline \multicolumn{7}{c}{ Panel A: Non Performing Loans (NPL) } \\
\hline Same group & $-0.0155^{* * *}$ & $-0.0225^{* * *}$ & $-0.0135^{* * *}$ & 0.00159 & $-0.0141^{* * *}$ \\
\multicolumn{1}{c}{$(3.766)$} & $(4.923)$ & $(2.837)$ & $(0.357)$ & $(2.954)$ \\
Nearby branch & & & & $-0.0181^{* * *}$ \\
& & & & $(3.528)$ \\
Length relationship & & & & $0.0156^{* * *}$ \\
& & & & & $(6.544)$ \\
Adj. $R^{2}$ & 0.004 & 0.016 & 0.157 & 0.565 & 0.158 \\
No. Obs & 133,669 & 132,991 & 117,048 & 72,367 & 117,048 \\
Dep. Var. Mean & 0.101 & 0.101 & 0.0992 & 0.0932 & 0.0992 \\
\hline
\end{tabular}

Panel B: Minor Anomalies

\begin{tabular}{lccccc}
\hline Same group & $-0.00881^{* *}$ & $-0.0183^{* * *}$ & $-0.00992^{* *}$ & 0.00311 & $-0.00104^{*}$ \\
& $(2.304)$ & $(4.318)$ & $(2.219)$ & $(0.663)$ & $\begin{array}{c}(2.330) \\
\text { Nearby branch }\end{array}$ \\
& & & & & $-0.0132^{* * *}$ \\
& & & & $(2.716)$ \\
& & & & $0.0134^{* * *}$ \\
Length relationship & & & & & $(5.936)$ \\
& & & & & \\
Adj. $R^{2}$ & 0.003 & 0.015 & 0.118 & 0.446 & 0.119 \\
No. Obs & 133,669 & 132,991 & 117,048 & 72,367 & 117,048 \\
Dep. Var. Mean & 0.0873 & 0.0872 & 0.0857 & 0.0781 & 0.0857 \\
\hline & & & & & \\
Fixed effects: & & & & & \\
Year & $\checkmark$ & $\checkmark$ & $\checkmark$ & $\checkmark$ & $\checkmark$ \\
Bank-Year & & & $\checkmark$ & $\checkmark$ & $\checkmark$ \\
Ind-Size-Age-Loc-Yr & & & & $\checkmark$ & \\
Firm-Year & & & & & \\
\hline
\end{tabular}

Notes: This table shows OLS estimates for Equation 2. The dependent variable in Panel A is a dummy that equals one if the loan granted by bank $b$ to firm $i$ is guaranteed by collateral. Mean dependent variable Panel A: 0.319. The dependent variable in Panel B is a dummy that equals one if the loan was signaled as Non Performing in the period $(t, t+3)$. Mean dependent variable Panel B: 0.101. The dependent variable in Panel $\mathrm{C}$ is a dummy that equals one if the loan was signaled as a Minor Anomaly (overdue, unlikely to pay, etc.) in the period $(t, t+3)$; minor anomalies are a subset of NPLs. Mean dependent variable in Panel C: 0.087. For Industry-Size-Age-Location-Year FE: Industry is defined at 3-digit Nace classification level. We consider 20 equally-sized size bins; age groups are based on the actual age (in years) of the firm. As for location we use the LLMs where the firm is located. ${ }^{*}, * *, * * *$ denotes significance at the $10 \% ; 5 \% ; 1 \%$ level, respectively. Standard errors clustered at bank-firm level 


\section{Online Appendix}

\section{A Classification of the manager's cultural origin}

A crucial aspect in our analysis is to classify firms and banks into their cultural group, namely German and Italian. To establish whether firms and banks are of Germanic or Italian cultural origin we analyze their boards using a method akin to Bedendo et al. (2018).

For each board member of each firm and bank, we utilized search algorithms that identify the most common: Germanic surnames; Germanic male given names; Germanic female given names; Italian surnames; Italian male given names; Italian female given names. Subsequently, a firm- or bank-board member is classified as having a Germanic cultural origin if all his/her given names and surname can be found in the Germanic listings, while he/she is classified as having an Italian cultural origin if given names and surname are in the Italian lists. We require that both the given name and the surname are Germanic (Italian) for a board member to be associated with a Germanic (Italian) origin. We then manually double-checked the allocation of each to the two categories to ensure that such requirement is satisfied.

Bedendo et al. (2018)'s approach basically classifies individuals into five categories: Italian, German, Mixed (e.g., a Germanic first name and an Italian surname or vice versa), Foreign, and Unclassified. Infocamere data provide us with the names of 31,525 firms' administrators (both managers and shareholders ). We use OR.SO. to retrieve names of 7,995 banks' administrators. We concentrate only on unambiguously Italian and German names that account for more than $90 \%$ of the sample, thus discarding all firms and banks that contain mixed, foreign, or unclassified managers. German individuals are $65 \%$ and $55 \%$, respectively, of firms' and banks' administrators. The share for firms basically reflects the share of German-speaking population in South Tyrol. The percentage for banks is lower because we consider all banks that operate in South Tyrol (even without a headquarter or a branch). 
A firm or a bank are defined German (Italian) if the majority $(50 \%+1)$ of its administrators are German (Italian). The choice of this threshold is basically inconsequential with respect to the robustness of the results. Figure A1 plots the share of Italian and German administrators for banks (Panel (A) and firms (Panel (B)); both graphs show that the distribution of the share of Italian (or German) administrators is predominately bimodal. Both banks and firms have either $100 \%$ or $0 \%$ share of Italian (or German) administrators. This result suggests that the choice of different thresholds would leave the attribution of cultural origin at bank and firm level basically unchanged.

Figure A1: Share of German administrators in banks and firms

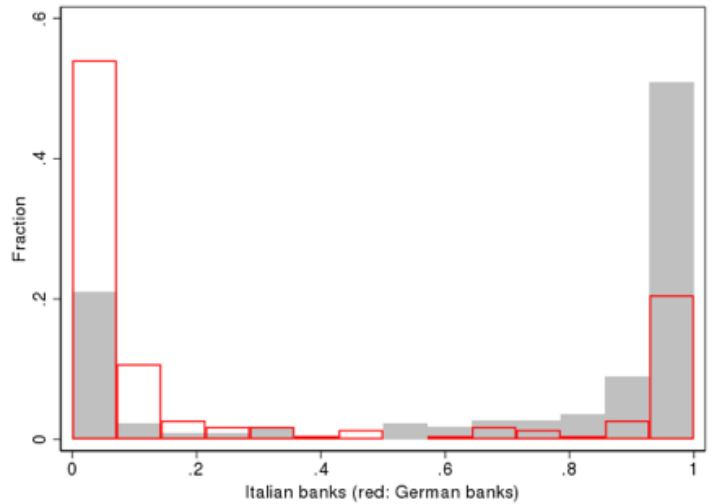

(a) Banks

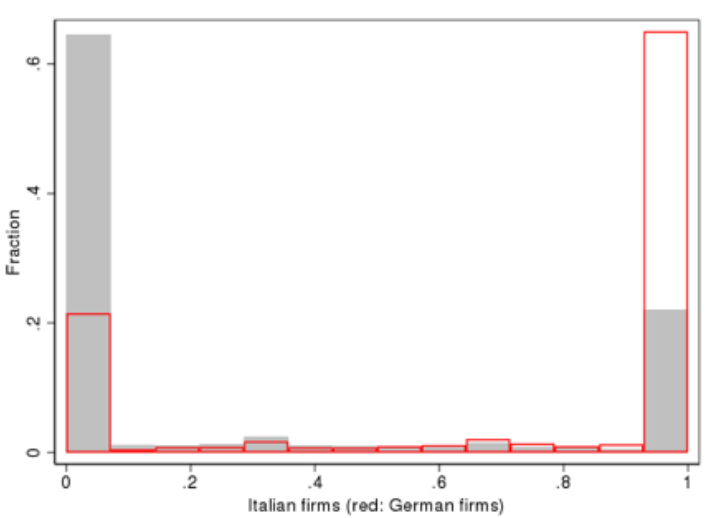

(b) Firms

Notes: Authors' calculation on CR-OR.SO.-Infocamere-INPS dataset. 


\section{B Characteristics of same-culture relationships}

\section{Table A1: Firm characteristics and same-culture relationships}

\begin{tabular}{lcc}
\hline & $(1)$ & $(2)$ \\
\hline & & \\
Age $(\log )$ & -0.00369 & $-0.0412^{* * *}$ \\
& $(0.624)$ & $(4.167)$ \\
Size $(\log )$ & $-0.0550^{* * *}$ & $-0.0779^{* * *}$ \\
& $(13.72)$ & $(11.98)$ \\
Growth & $0.00476^{* *}$ & 0.00209 \\
& $(2.039)$ & $(0.528)$ \\
Tangibility & & $0.189^{* * *}$ \\
& & $(6.120)$ \\
Profitability & & $-0.225^{* * *}$ \\
& & $(3.777)$ \\
Leverage & & $-0.190^{* * *}$ \\
Cash & & $(7.142)$ \\
Cash Flow & & $0.165^{* *}$ \\
& & $(2.086)$ \\
Medium Risk & & $0.374^{* * *}$ \\
& & $(4.549)$ \\
High Risk & & -0.0174 \\
& & $(1.142)$ \\
Year FE & $\checkmark$ & $(1.113)$ \\
Industry FE & $\checkmark$ & $\checkmark$ \\
LLM FE & $\checkmark$ & $\checkmark$ \\
Observations & 62,283 & 19,346 \\
Adjusted $R^{2}$ & 0.128 & 0.151 \\
\hline
\end{tabular}

Notes: The sample corresponds to firm-year observations of firms headquartered in the South Tyrol region and included in the Italian credit registry between years 2005 and 2015. Coefficients correspond to OLS estimates for a regression equation in which the dependent variable is a dummy that equals one if all of the firm's banking relationships correspond to banks of the same cultural group, 0 if the firm has at least one relationship with a bank of a different group. Age is the natural logarithm of one plus firm age (measured in years). Size is the natural logarithm of the number of employees of the firm. Leverage is the ratio of total debt to total assets. Profitability is the ratio of earnings before interest and taxes (EBIT) to total assets. Tangibility is the ratio of total fixed assets to total assets. Cash is the ratio of cash to total assets. Cash flow is the ratio of cash flows to total assets. Sector fixed effects (FE) are dummy variables indicating the industrial sector of the firm. LLM FE are 14 indicator variables for the local labor market where the firm is located. All other variables are defined in Table 3. T-statistics are in parenthesis. *, **, *** denotes significance at the 10\%; 5\%; $1 \%$ level, respectively. Standard errors clustered at firm level 


\section{Table A2: Bank characteristics and same-group relationships}

\begin{tabular}{lcc}
\hline & $(1)$ & $(2)$ \\
\hline & & \\
BCC & $0.110^{* * *}$ & $0.113^{* * *}$ \\
& $(6.450)$ & $(6.797)$ \\
Total assets $(\log )$ & $-0.0564^{* * *}$ & $-0.0466^{* * *}$ \\
& $(14.40)$ & $(12.06)$ \\
Capital ratio & $1.515^{* * *}$ & $1.588^{* * *}$ \\
& $(10.50)$ & $(11.24)$ \\
ROA & 1.216 & 2.042 \\
& $(0.722)$ & $(1.242)$ \\
ROE & 0.0707 & 0.0115 \\
& $(0.494)$ & $(0.0822)$ \\
NPL ratio & $-0.276^{* * *}$ & $-0.309^{* * *}$ \\
& $(2.932)$ & $(3.359)$ \\
Coverage ratio & $0.144^{* * *}$ & $0.101^{* *}$ \\
& $(3.462)$ & $(2.477)$ \\
Year FE & $\checkmark$ & $\checkmark$ \\
LLM FE & & $\checkmark$ \\
& & \\
Observations & 5,322 & 5,322 \\
Adjusted $R^{2}$ & 0.296 & 0.331 \\
\hline
\end{tabular}

Notes: The sample corresponds to bank-year observations for banks lending to firms headquartered in the South Tyrol and included in the Italian credit registry between years 2005 and 2015. Coefficients correspond to OLS estimates for a regression in which the dependent variable is the fraction of firms borrowing from the bank which belong to the same cultural group. $B C C$ is a dummy variable taking a one if the bank is a credit cooperative (Banca di Credito Cooperativo (BCC)). NPL ratio is the ratio between non performing loans (NPL) and total loans. Coverage ratio is the ratio between credit risk adjustments and NPL. ROA is the ratio between bank net income and total assets. $R O E$ is the ratio between net income and total equity. *, **, $* * *$ denotes significance at the $10 \% ; 5 \% ; 1 \%$ level, respectively. Standard errors clustered at firm level 


\section{Robustness Checks and Additional Analysis}

Table A3: Collateral requirements in term loans

\begin{tabular}{lccccc}
\hline & $(1)$ & $(2)$ & $(3)$ & $(4)$ & $(5)$ \\
\hline Same group & & & & & \\
& $0.0482^{* * *}$ & $-0.0289^{* * *}$ & -0.00889 & -0.0161 & -0.0114 \\
Nearby branch & $(4.802)$ & $(2.834)$ & $(0.764)$ & $(0.869)$ & $(0.983)$ \\
& & & & & $-0.0228^{*}$ \\
& & & & $(1.772)$ \\
Relationship length & & & & & $0.0761^{* * *}$ \\
& & & & & $(12.14)$ \\
Adjusted $R^{2}$ & 0.005 & 0.122 & 0.252 & 0.472 & 0.261 \\
Observations & 61531 & 60981 & 47391 & 19091 & 47391 \\
Dep. Var. Mean & 0.560 & 0.561 & 0.575 & 0.513 & 0.575 \\
\hline & & & & & \\
Fixed effects: & & & & & \\
Year & $\checkmark$ & & & $\checkmark$ & $\checkmark$ \\
Bank-Year & & $\checkmark$ & $\checkmark$ & $\checkmark$ & $\checkmark$ \\
Ind-Size-Age-Loc-Yr & & $\checkmark$ & & & \\
Firm-Year & & & & & \\
\hline
\end{tabular}

Notes: This table shows OLS estimates for Equation 2. The sample corresponds to firm-bank-year observations in the Credit Registry in which the firm's share of term loans over outstanding debt from the bank is larger than $50 \%$. The dependent variable is a dummy variable equal to one if the bank required the firm to post collateral on at least one of the loans in the year.. Mean dependent variable: $0.56 .{ }^{*},{ }^{* *},{ }^{* * *}$ denotes significance at the 10\%; $5 \% ; 1 \%$ level, respectively. Standard errors clustered at bank-firm level 